IZA DP No. 9131

"A Flop or a Success?" An Evaluation of the Welfare Impacts of the 6-3-3-4 Education System in Nigeria

Ruth Uwaifo Oyelere

June 2015 


\title{
"A Flop or a Success?" \\ An Evaluation of the Welfare Impacts of the 6-3-3-4 Education System in Nigeria
}

\author{
Ruth Uwaifo Oyelere \\ Emory University \\ and IZA
}

\section{Discussion Paper No. 9131 \\ June 2015}

IZA
P.O. Box 7240
53072 Bonn
Germany

Phone: +49-228-3894-0

Fax: +49-228-3894-180

E-mail: iza@iza.org

\begin{abstract}
Any opinions expressed here are those of the author(s) and not those of IZA. Research published in this series may include views on policy, but the institute itself takes no institutional policy positions. The IZA research network is committed to the IZA Guiding Principles of Research Integrity.

The Institute for the Study of Labor (IZA) in Bonn is a local and virtual international research center and a place of communication between science, politics and business. IZA is an independent nonprofit organization supported by Deutsche Post Foundation. The center is associated with the University of Bonn and offers a stimulating research environment through its international network, workshops and conferences, data service, project support, research visits and doctoral program. IZA engages in (i) original and internationally competitive research in all fields of labor economics, (ii) development of policy concepts, and (iii) dissemination of research results and concepts to the interested public.
\end{abstract}

IZA Discussion Papers often represent preliminary work and are circulated to encourage discussion. Citation of such a paper should account for its provisional character. A revised version may be available directly from the author. 


\section{ABSTRACT \\ "A Flop or a Success?" An Evaluation of the Welfare Impacts of the 6-3-3-4 Education System in Nigeria}

The need for graduates who would be productive citizens able to contribute significantly to the Nigerian economy led to the overhaul of the old education system 6-5-4 and the implementation of the 6-3-3-4 system, with its first set of graduates from secondary schools in 1988. The main objective of the 6-3-3- 4 system was to produce self-reliant graduates with better labor market skills and earning potential. In this paper, we investigate to what extent this goal was achieved. Using a Regression Discontinuity (RD) design, we examine if graduates from the 6-3-3-4 system experienced an improvement in welfare compared to those from the old system. We measure welfare improvement using several indicators such as a decline in poverty likelihood and poverty gap, an increase in the probability of employment and an increase in wages. Our results provide some evidence that the new system led to a decrease in the likelihood of being poor compared to those who passed through the old system. We also provide evidence of higher wages for select participants. We do not find any consistent evidence that the 6-3-3-4 system increased the probability of being employed when we compare participants from both systems. Our results suggest that while the system change may not have met some of its critical objectives, it cannot be viewed as totally ineffective.

JEL Classification: I25, I38, O15, O12, O20

Keywords: education system, Nigeria, poverty incidence, employment, 6-3-3-4, 6-5-4, wages, RDD, program evaluation

Corresponding author:

Ruth Uwaifo Oyelere

Emory University

Department of Economics

Rich Memorial Building

Atlanta, GA 30322-2240

USA

E-mail: ruth.oyelere@emory.edu 


\section{Introduction}

With the introduction of the New National Policy on Education in 1981, plans were underway to overhaul the prior Nigerian education system. According to Fabunmi (1986) the previous education system was deemed archaic and there was need for a modern, dynamic and progressive educational system. These plans gave birth to the 6-3-3-4 system. A system that allowed for six years in primary school, three years in Junior Secondary School (JSS), three years in Senior Secondary School (SSS) and the last four years were for tertiary education. Previously Nigeria had a 6-5-4 system, which represents six years in primary school, five in secondary school and four years of tertiary education. Prior to 1980, there were several debates on the inadequacy of the 6-5-4 system to prepare Nigerians to face whatever challenges, including employment problems, they may come across in future. These discussions and a general dissatisfaction with the 6-5-4 system were the motivation for replacing it with the 6-3-3-4 system. One of the objectives of 6-3-3-4 was to produce graduates who would be able to make use of their hands, heads and hearts. This implies an education that was more holistic, relevant and one that should lead to higher human capital accumulation, economic growth and improved welfare.

The move to 6-3-3-4 was not only about the change in the number of years of secondary education (from 5 to 6 ), or the division of secondary education into two parts with certifications at the end of each part. The system overhaul also involved a radical change in the subject structure of education in secondary school. Also at the tertiary level, a professional orientation was adopted to minimize unemployment and produce skilled labor in science and technology. The 6-3-3-4 system was supposed to be a functional education meaning an education that as noted in Uwaifo and Uddin (2009), allows those who pass through it function 
economically, intellectually, morally, politically and socially.

From the early 2000 s about 20 years after the program was first rolled out, there was an increase in debates among education policy makers and education interest groups about the effectiveness of the education system. One view is that the system if implemented correctly would yield success but in the Nigerian case had not been implemented properly but still better prepared individuals for labor market success than the previous system. Hence, individual who passed through the 6-3-3-4 education embody more human capital than their counterparts who passed through the 6-5-4 system. This view was championed by the late Prof Fafunwa, the Minister of Education during the period of the system's inception. The other more commonly held view was that the system flopped and should be overhauled as graduates via this system embodied less human capital and have lower earning potential. ${ }^{1}$ The later more common view and sentiment about the system finally led to its replacement 24 years after its inception with the new 9-3-4 system of Education [Universal Basic Education (UBE)] in 2006 which kicked off formally in 2008 .

Given the emphasis of the 6-3-3-4 education system was in producing selfreliant citizens with a functional education, we examine in this paper to what extent this goal was met with respect to improving welfare of individuals who were exposed to the system compared to those who passed through the previous system. Further, as the 6-3-3-4 system of education was supposed to be job-oriented and mitigate the significant rate of unemployment and skill mismatch, we also examine to what extent the system increased the probability of employment in comparison to graduates of the former system. Using data from the 2010 LSMS survey on

\footnotetext{
${ }^{1}$ As noted in a national newspaper, January 14, 2004, Deputy Vice-Chancellor, Ahmadu Bello University (ABU), Zaria and one of the architects of the 6-3-3-4 system of education in Nigeria, Professor Ogunshola, reflects on his life at 80 and regrets the setback the system brought to the nation's education system in his provoking interview with Ayodeji Fashikun.
} 
Nigeria, that allows us to compares a sizeable number of individuals who passed through both systems, we address two specific questions. First, does the 6-3-34 system lead to an improvement in welfare of participants compared to those who passed through the 6-5-4 system? Second, does the 6-3-3-4 system lead to a higher probability of employment for its participants in comparison to those who passed through the 6-5-4 system. We address these questions by calculating local treatment effects employing a sharp Regression Discontinuity (RD) design. We make use of Calonico, Cattaneo, and Titiunik (2014)'s nonparametric based inference procedure for estimating treatment effects in $\mathrm{RD}$ designs. We focus on estimated treatment effects using a local polynomial estimator with a quadratic local polynomial bias correction. For deducing inferences, we employ Calonico, Cattaneo, and Titiunik (2014b) bias-corrected inference procedure which is robust to large bandwidth choices.

We estimate treatment using the RD approach on the general sample and several sub-samples. In particular we focus more on treatment effects on the sample of individuals whose highest qualification is at the secondary level. Our rationale for focusing on this group is the fact that most of the changes implemented with the system overhaul affected secondary education. Moreover, some of the curriculum change that accompanied the 6-3-3-4 system was geared towards individuals who would be going from secondary school to the work force. Hence, most of the discernable effects of the 6-3-3-4 system if at all they exist would be more evident among those who received only a secondary qualification through this system.

Our results provide evidence that the 6-3-3-4 system led to welfare improvements. In particular compared to individuals who were exposed to the old system, we find that participants of the 6-3-3-4 whose highest qualification is at the secondary level have a $13.8 \%$ lower incidence of extreme poverty. We are also able to deduce the potential source of this decrease in poverty from increased wages. We 
find about a $38.2 \%$ increase in wages for individuals with secondary qualification who passed through the 6-3-3-4 system. We do not find consistent evidence that the system led to an increase in the probability of being employed. However this result does not suggest that the system change did not boost employment given the significant population growth that directly increased the size of the cohort exposed to 6-3-3-4. Rather finding no decline in employment probability in the 6-3-3-4 cohort, despite the increase in the length of the school to work transition and the rapid population growth over time, may be viewed as a testament to increased self-reliance among graduates from this system.

Our paper contributes to the literature by investigating empirically welfare impacts of the 6-3-3-4 system in Nigeria using a RD design with bias correction and a robust inference procedure. Nigeria has the largest population in Africa and is home to a sizeable amount of human capital and manpower in Africa. Given the role of education in manpower development and economic growth, an evaluation of the effectiveness of one of its longest lasting education systems that was replaced in 2006 with the UBE is important. Although past literature has considered the 6-3-3-4 system and its deficiencies with respect to implementation, there has not been any prior attempt to compare graduates via this system and any other system in an empirical way. To the best of our knowledge, our paper provides the first attempt at doing this. Moreover given recent conversations by policy makers on the ineffectiveness of the 9-3-4 system and the need to return to some variance of the 6-3-3-4 system, the need for an evaluation of this system is expedient and timely. ${ }^{2}$ Our paper also contributes to the literature by highlighting the need for policy makers to evaluate programs empirically before concluding

\footnotetext{
${ }^{2}$ The June 28, 2012 Vanguard Newspaper highlights this quandary on education systems in Nigeria and the suggestion of the former Education Minister, Prof. Uqayyatu Rufa'i to revert back to the 6-3-3-4 system.
} 
about their effectiveness. Though the 6-3-3-4 system was plagued with suboptimal implementation, we show that the system was not totally a flop as is portrayed in the past literature and echoed in popular media. Finally our paper contributes to the general literature that evaluates education policies and programs. What is unique about this analysis is that we consider a national system change while most other analysis focus on local programs and specific education policy shifts.

The rest of our paper proceeds as follows. In section two we provide more information on the 6-3-3-4 system and briefly review the past relevant literature. Section three is a summary of the data sets and descriptive analysis. Our empirical model is highlighted in section four, and section five provides a detailed summary of our finding and robustness checks. We summarize and conclude in section six.

\section{Background and Relevant Literature}

\subsection{Background}

A change in an education system is a huge undertaking that is both costly monetarily but also imposes costs on individuals who are affected by the change in the education system. Historically, countries do not change education systems frequently but the Nigerian experience in particular has been somewhat different given a change in education system twice in less than 40 years. ${ }^{3}$

Prior to 1982 Nigeria followed the 6-5-4 system which represents six years in primary school, five in secondary and four in tertiary and in terms of curriculum was very similar to the system inherited from the British via colonial rule. The foundation for the 6-3-3-4 system was laid following the introduction of the New National Policy on Education in 1981. The policy aimed at realizing a self-reliant and self-sufficient nation to meet the country's developmental needs and this major

\footnotetext{
${ }^{3}$ For a more in-depth historical perspective of early education systems in Nigeria, see Fafunwa 1974 and Imam (2012).
} 
reform in its education system was a significant part of how this policy objectives were going to the achieved.

One of the motivation for the move to the 6-3-3-4 system was the dire need for technological development in Nigeria to meet the challenges of the changing global economy and the failure of the the 6-5-4 system to produce graduates who could meet this need. Moreover the failure of the 6-5-4 system to produce graduates who had relevant skills that increased employability or the possibility of self-reliance through entrepreneurship provided further incentive to overhaul the education system and introduce one that could fulfil this and other critical objectives. Under the 6-3-3-4 system a student is expected to spend six years for primary education, three years for JSS, three years for SSS and four years for tertiary. The focus of the new education policy implemented in 1981 was to build technical capacities of students right from secondary school level. This focus on technical human capital accumulation at the secondary level has two advantages. First it would increase the likelihood that secondary school graduates, who do not go on to tertiary institution, will be able to make use of their hands, heads and hearts and build self-reliance. An increase in self reliant secondary graduate should reduce unemployment and improve welfare. Second as noted in Thovoethin (2012), a focus on technical courses would better prepare students to better engage in engineering and technological related courses and careers in tertiary institutions.

The 6-3-3-4 system made it possible for vocational education to be taught at all levels of education. In particular the program focused on merging academic and vocational education programs with an emphasis on acquiring vocational skills at the secondary level. To realize this goal, at the Junior Secondary School (JSS) level, vocational subjects such as home economics, introductory technology, business studies and agricultural science were made compulsory for both sexes and students also had to take English, mathematics, integrated science, social studies, 
fine art, health education, physical education and music. Further, a student is expected to select a Nigerian language and to choose either Christian religious knowledge or Islamic religious knowledge. At the Senior Secondary School (SSS) level students are required to study English, mathematics, one science subject and one Nigerian language. Other subjects are electives and students are supposed to select based on their interest in Sciences, Social Sciences or the Arts. The 6-3-3-4 system led to the introduction of a wide range of electives at the SSS levels. Available subjects included biology, geography, literature in English, commerce, physics, economics, chemistry, home management, food and nutrition, computer science/typing, French, music, wood work, history, technical drawing, auto mechanics, applied electricity, agriculture, arabic, government, accounting, Christian religious knowledge, Islamic religious knowledge, metal work, visual and physical education. ${ }^{4}$ The subjects offered through the 6-3-3-4 system reflect the job-oriented objective of the system. As noted in Uwaifo and Uddin (2009) emphasis was placed on manual activities, technical proficiency, economic efficiency and the respect for the dignity of labor.

At its inception the program had huge support and there were high hopes for the program as it was viewed as noted in Uwaifo and Uddin (2009) a laudable programme capable of ushering in an educational revolution in Nigeria and the right direction, towards the technological development of the nation. Unfortunately, the next 24 years did not seem to yield the expected outcomes. Anecdotal evidence suggest that the program was a flop and as noted above, some individuals who had championed its implementation came to view it as a wrong step for Nigeria while others linked its lack of effectiveness to poor implementation.

\footnotetext{
${ }^{4}$ It is important to mention that not all schools offered all the above listed electives at the SSS level. Hence students to some extent under the guidance of their parents, chose schools that would offer the kind of electives they were interested in.
} 
In 2006 amidst significant criticism of the 6-3-3-4 system but without significant empirical research comparing its participant to participants of the prior 6-5-4 system, the system was replaced formally with the 9-3-4 system. At the core of the newest system is the Universal Basic Education, (UBE) which involves 9 years of uninterrupted schooling with an automatic transfer from one class to the other (6 years of primary school education and 3 years of Junior Secondary School education). This UBE is a replacement for the Universal Primary Education (UPE) scheme of the 6-3-3-4 system of primary education. Two major change in the 9-3-4 system is the removal of the entrance exam to secondary school characteristic of the 6-3-3-4 system and making 9 years of schooling free and compulsory compared to 6 years of compulsory education in the 6-3-3-4 system and free schooling which characterised the system from 1981-1999. The 9-3-4 is supposed to be designed to conform with the millennium development goals (MDG) of basic education for all.

\subsection{Relevant Literature}

Impact analysis of policy and programs has become quite common in the economic and public policy empirical literature. In many cases education, welfare and health related impacts of programs and policies are evaluated through an artificial randomized experiment. An example of such a paper is Angrist and Lavy (2003) who consider the effect of high school matriculation awards on education outcomes. Another is Krueger and Zhu(2003) who investigate the effect of school vouchers in New York. Similarly Rouse (1998) considers the impact on student achievement of private school vouchers administered through the Milwaukee Parental Choice Program. The effect of financial aid offers on college enrollment was also considered by Van der Klaauw (2002). Jacob and Lefgren, (2006) consider the impact of remedial education on achievement and Matsudaira (2008) estimates the impact 
of mandatory summer school on student achievement. ${ }^{5}$

It is also worth noting that the literature evaluating micro-education programs in developing countries has grown significantly over the last 10 years with the increase in randomized trials in many developing countries. This increase in the literature is especially true for research focused on the impact of micro or macro programs and polices on education outcomes like enrollment, achievement and education attainment. For example Kremer et al (2004) considers the impact of different school inputs on learning in Kenya while Kremer and Miguel (2004) consider the effect of deworming children on education and health related outcomes also in Kenya. Another example is McEwan and Shapiro (2008) who consider the benefits of delayed enrollment in Chile. In other scenarios, natural experiments occur that allow us to estimate the impact of exogenously determined conditions on socioeconomic variables we are interested in. Angrist, Bettinger, Bloom, King, Elizabeth and Kremer (2002) consider private school voucher in Colombia and in a follow up to this paper, Angrist and Bettinger (2005) consider the long term consequences of the secondary school vouchers received by students. There are also papers that have considered in a non-randomised setting, the impact of other school related programs that are specific to a country or countries. For example, Dynarski (2003) considers the consequences of merit aid, Andrabi, Das, and Khwaja (2006) examine the effect of government girls schooling expansion in Pakistan on primary school enrollment during the 1990s, Howell and Petersom (2002) investigate the impact of vouchers on the education gap, Duflo (2001) estimates the impact of a school construction program on school attainment in Indonesia and Krueger and Whitmore (2001) investigate the effect of attending small classes at early grades on outcomes later on in life. Many of the aforementioned papers found strong impacts of program or policy intervention on schooling outcomes like

\footnotetext{
${ }^{5}$ Other related papers include Angrist and Lavy (1999) and Ludwig and Miller (2007).
} 
enrollment, school attainment, school attendance or performance. However, not all programs upon evaluation had the expected impact on schooling and health related outcomes.

In contrast there is a smaller set of papers that examine macroeconomic programs and policies and their effect on welfare and labor market outcomes like poverty reduction, reduction in risk of unemployment or returns to education. For example the impact of PROGRESA (now called Oportunidades) in Mexico on health, education and labor market outcomes has been examined extensively. ${ }^{6}$ Other examples that fit this sub-group are Jalan and Ravallion (2003) who examine the poverty impact of Argentina's Trabajar workfare program and Gonzalez and Uwaifo Oyelere (2011) who estimate the impact of Mission Sucre a nationwide education policy change in Venezuela on returns to education. Other related papers that look at the effect of macroeconomic or institutional changes and the effect on welfare and labor market outcomes include Fleisher et al (2005) who link changing returns to education to reforms that came along with institutional change and Uwaifo Oyelere (2011) who provides evidence of the impact of democratic reforms on returns to education in Nigeria.

In terms of papers that have evaluated education systems in Nigeria, the literature is scant. Specific papers that have discussed the 6-3-3-4 system include Uwaifo and Uddin (2009) who examine the implementation of the technology subjects' aspect of the 6-3-3-4 system of education using Ekpoma a city in Nigeria as a case study. These authors find significant problems with program implementation and also a deficit of personnel and materials to support the system. Another related paper discussing why the system failed is Thovoethin (2009). This paper argues

\footnotetext{
${ }^{6}$ Papers examining effects on schooling include Schultz 2004; de Janvry (2006) and Todd and Wolpin 2006. For labor-market outcomes for adults and youth see Behrman, Parker, and Todd (2009).
} 
that the concurrent rise of private education at the early phase of the 6-3-3-4 led to the system's failure to meet its objectives. Imam (2012) reviews educational policy in Nigeria since 1944, highlighting details about the 6-3-3-4 system and its implementation. The three aforemention papers though useful do not evaluate this system's welfare impacts empirically although each provides some evidence and (or) arguments about the documented problems/issues with the system. This gap in the literature is one of the underlining motivations for this paper. We focus on the impact of the education system change on individuals' poverty risk, wages and employability primarily because of the clear link between the 6-3-3-4 system's goals and objectives and these outcomes.

\section{Data and Descriptive Analysis}

\subsection{General Data Description}

For this analysis, we make use of the Nigeria General Household Survey (GHSPanel) 2010/2011 and the GHS 2010/2011 survey. The GHS is a cross-sectional annual survey of households in Nigeria conducted by the Nigerian Bureau of Statistics (NBS). In terms of coverage the survey covers the Federal Capital Territory (FCT), Abuja and the 36 states. Within each state, both urban and rural enumeration areas (EAs) were sampled. In 2010 the survey was significantly revised and a panel component was added. The 2010/2011 survey contains about 22,000 households. Its panel component is focused on 5000 households within the GHS and covers multiple agricultural activities. Both the GHS general survey and the GHS-Panel are nationally representative surveys which are representative at the zonal (urban and rural) levels. According to the National Bureau of Statistics (NBS), the focus of the panel survey is to improve data from the agriculture sector and link this to other facets of household behavior and characteristics. The 
revisions of the GHS survey as well as its panel components is a joint effort of NBS partnering with the Federal Ministry of Agriculture and Rural Development (FMA \& RD), the National Food Reserve Agency (NFRA), the Bill and Melinda Gates Foundation (BMGF) and the World Bank. This panel component is focused on getting better information on the role of agriculture in households' economic wellbeing. The panel aspect of the survey draws heavily on the Harmonized Nigerian Living Standard Survey (HNLSS) and the National Agricultural Sample Survey (NASS).

The GHS Panel consist of two survey stages the post-planting period and the post-harvest period. The post-planting period survey took place late 2010 while the post-harvest survey took place in 2011. The post-planting survey includes 22,000 households while the post-harvest survey includes just the panel sample. The goal is for the GHS Panel to be repeated every two years while the GHS Cross Section will continue to be carried out annually. The survey consists of three questionnaires that cover a wide range of socioeconomic topics: the Household Questionnaire, the Agricultural Questionnaire and the Community Questionnaire. In this analysis we will not be making use of the panel aspect of the GHS data because our chosen methodology for answering our questions of interest does not require panel data. However we will be focusing solely on the panel sample of 5000 households and about 27,000 observations. The GHS 2010/2011 survey is more detailed than previous GHS and covers a wide range of socio-economic topics. We restrict ourselves to the 5000 panel sample because we focus on parts of the post-planting and the post-harvest household questionnaire in this analysis. These questionnaires contains information on observations' demographic and migration characteristics, education, labor market characteristics, credit and savings, household assets, non-farm enterprizes, household food and non-food expenditures, food security and other non-labor income. 


\subsection{Defining Treatment (Participation in the 6-3-3-4 system)}

There is no question in the GHS survey that asks respondents specifically what system of education individuals passed through. However we can easily infer participation (treatment) in the new educational system based on time of birth. ${ }^{7}$ The typical age in Nigeria in primary one is 6 year and given the first group of graduates from the 6-3-3-4 finished high school in 1988, assuming normal education progress, we can deduce that these individuals were born in 1971. Hence we allocate treatment (passing through the 6-3-3-4) to anyone who was born from 1971 onwards to 1999 and the non-treated are those born before $1971 .^{8}$ This method of allocating treatment has two potential limitations. First if someone happens to have progressed through the education system at a faster rate than normal, they may have been born in 1971 but not experienced treatment. This could happen if the individual got double promoted (skipped a grade) in elementary school and hence missed treatment. Skipping grades or getting double promoted in Nigeria is not common so we do not worry about this potential limitation. In contrast, some individuals born before 1971 may have repeated a grade in primary school or began school a little bit older and hence experienced treatment but will be wrongly allocated to non-treatment. This possibility is much more likely as grade repetition though not very common occurs. ${ }^{9}$ More importantly, there is evidence more so in rural areas than in urban that individuals may begin school at older ages. If this happens, individuals born before 1971 who began school late can be wrongly assigned to non-treatment and this could reduce the possibility of finding

\footnotetext{
${ }^{7}$ Hereon we would use treatment interchangeably with exposure, new program and participation in 6-3-3-4 and we will use the words control, non-treated and old program when referring to those who passed through the 6-5-4 system.

${ }^{8}$ Those born from 2000 onward will pass through the 9-3-4 system. We do not consider these individuals as they are 10 years or younger in our dataset and are not in our relevant sample for analysis.

${ }^{9}$ About $4.5 \%$ of current students in our data have repeated a grade according to our data.
} 
significant effects. Later on in the paper we discuss how we address this potential challenge.

\subsection{Descriptive Analysis}

In searching for evidence of welfare impacts of the 6-3-3-4 system, a good starting point is to compare the distribution of per capita expenditure (PCE) for the treatment group (those who passed through the 6-3-3-4 system) and our control group (those who passed through the 6-5-4 system). Figure 1 highlights kernel density distribution of PCE. Figure 1A captures the treated and control group distribution for the general sample. While Figure 1B highlights the distributions for a sub-sample. The sub-sample depicted here are those whose highest qualification is at the secondary level and who are in the most relevant birth cohort for our empirical analysis. Examining this sub-sample is useful because the effect of treatment should be more easily discernable for those whose highest qualification is at the secondary level and who are born in the same age cohort. A focus on those with secondary qualification is important because most of the changes implemented through the 6-3-3-4 education system affected secondary education directly. In addition, our empirical strategy is based on a RD design which is focused on estimating average effect for a subpopulation, close to a set cutoff, which in our case is a 1971 year of birth. The age cohort we restrict the sample in Figure 1b to is those born between 1966 and 1975. Both Figure 1a and 1b show a slight rightward shift in the distribution for the treated. The slight rightward shift in the distribution is more evident in the sub-sample.

This figure may suggests some possible welfare improvement for the treated sample but given the closeness of the distributions, these figures do not provide substantial evidence of welfare improvement from treatment. We also examine wages as a potential source of the increased PCE. Wages may increase as a result 

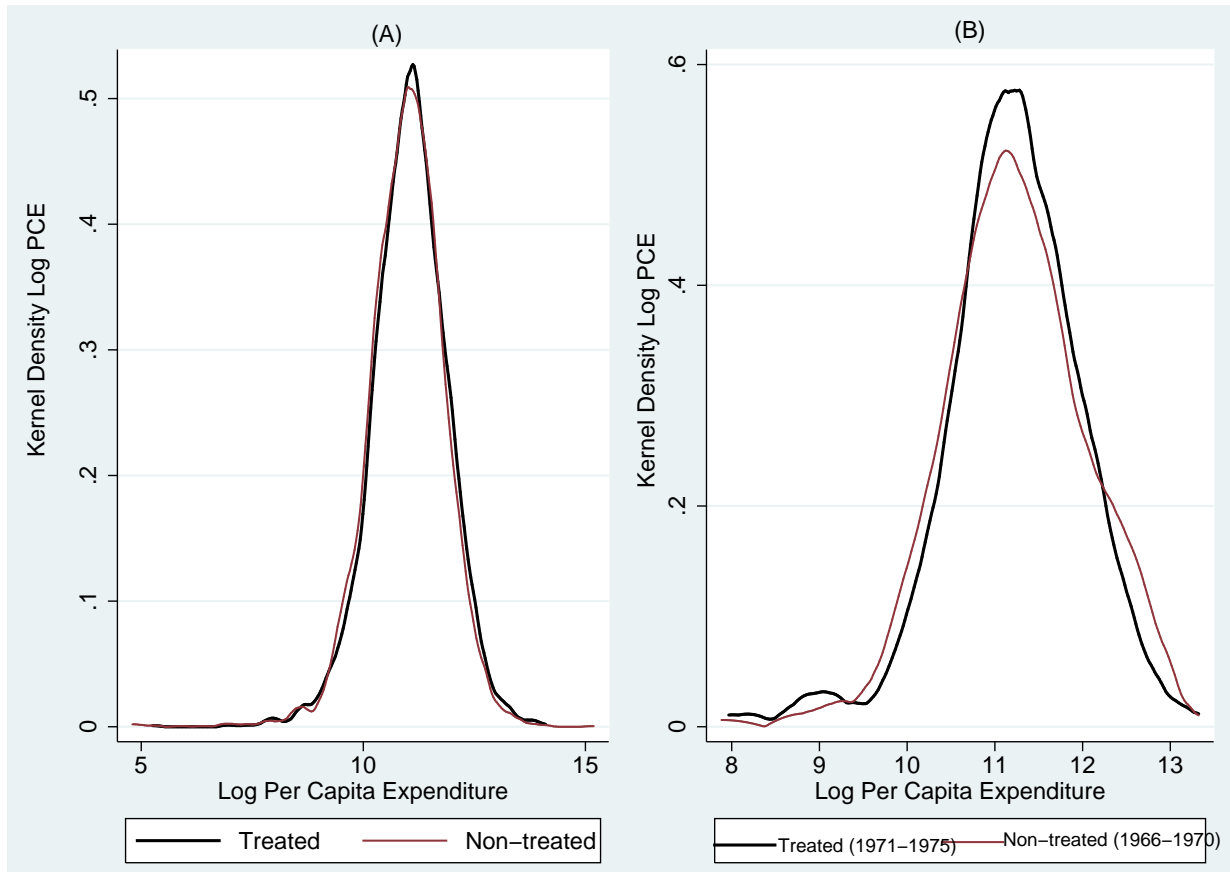

Figure 1: PCE Kernel Distribution for 6-5-4 and 6-3-3-4 System Participants

of exposure to treatment since higher human capital accumulation is an expectation from exposure to the treatment. Figure $2 \mathrm{a}$ and $\mathrm{b}$ highlight the kernel density distribution of wages for the treated and control groups. Just as in figure 1 we present distributions for the full sample and the aforementioned sub-sample. Figure 2a does not provide support for a positive shift in the wage distribution for the treated group as a whole. However this is not surprising because wages increase with experience and experience increases with age. Since the control group is older than the treated group, finding the distribution of the control group slightly to the right of the treated groups is consistent with the age earning profile. However, the closeness of the distributions may be suggestive of some benefits from treatment. Figure $2 \mathrm{~b}$ which is focused on the sub-sample within the same age cohort 
we described above, provides some suggestive evidence of positive benefits from 6-3-3-4. The wage distribution of the treated restricted sample is slightly to the right of the control.
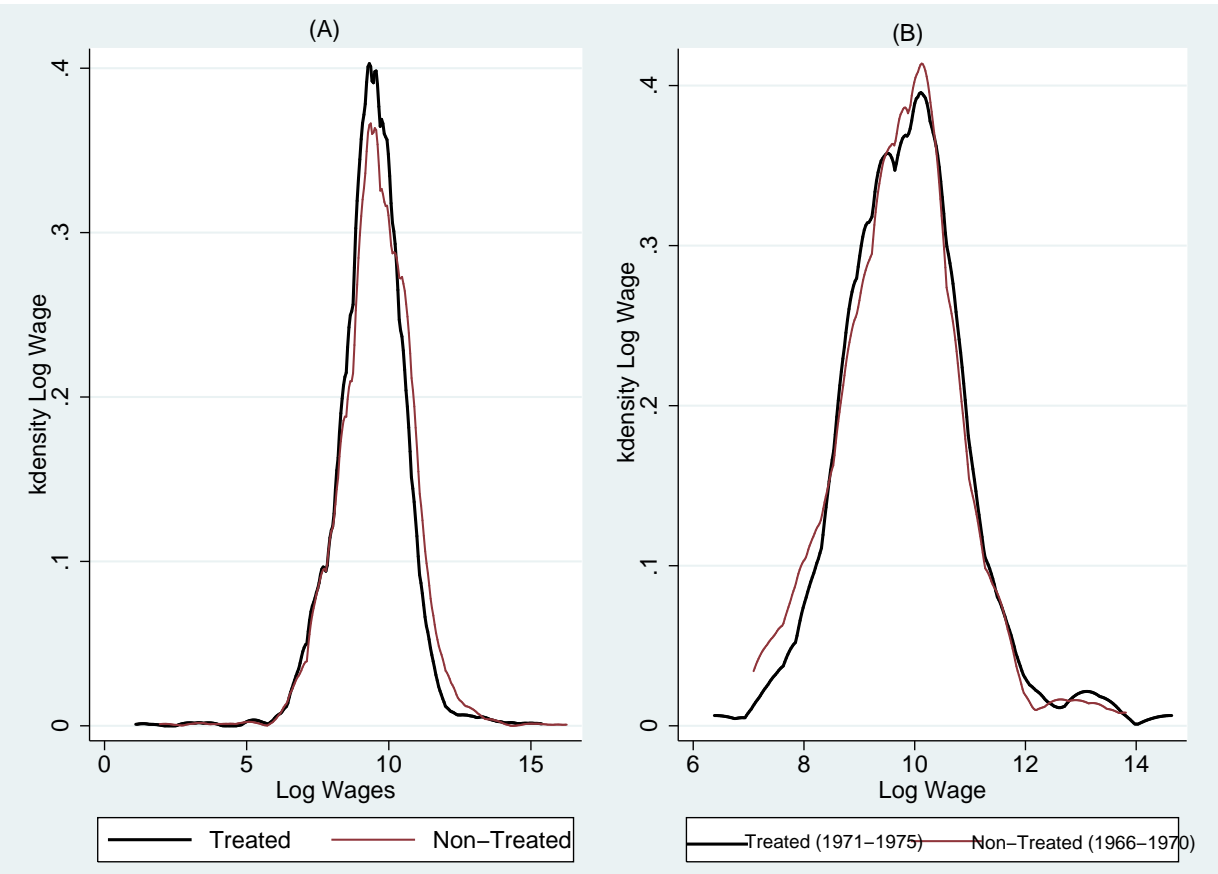

Figure 2: Log Wage Kernel Distribution for 6-5-4 and 6-3-3-4 System Participants

The last measure of welfare we consider in this descriptive analysis is employment. Figure 3 provides bar graphs of the share employed by treatment status. Figure 3a provides shares for the whole population while Figure 3b provides share for the same sub-sample, those with secondary level qualification and born in the most relevant cohort for our analysis. Both figures suggest that the treated group has a smaller share employed than the control group. However the difference is significantly smaller when we focus on the sub-sample. These figures may suggest that treatment did not increase the share employed. However rigorous analysis is 
needed to confirm this hypothesis. Furthermore, given the rapid increase in population in Nigeria, the differences in means noted in Figure 3a and b do not suggest that the treatment had no effect on employment. Instead what these differences may capture is that the growth rate of population may not have kept pace with the increase in opportunities for the treatment group who are younger and entered the work force on average at a later time. Meaning that even if the 6-3-3-4 program had positive effects in terms of boosting human capital and increasing earning potential, if population grows much faster than expansion of output and employment opportunities, the share employed might keep shrinking despite a larger absolute number employed as a result of treatment. In our econometric analysis we make use of a regression discontinuity design in an attempt to identify consistent effects of treatment on employment.

(A)

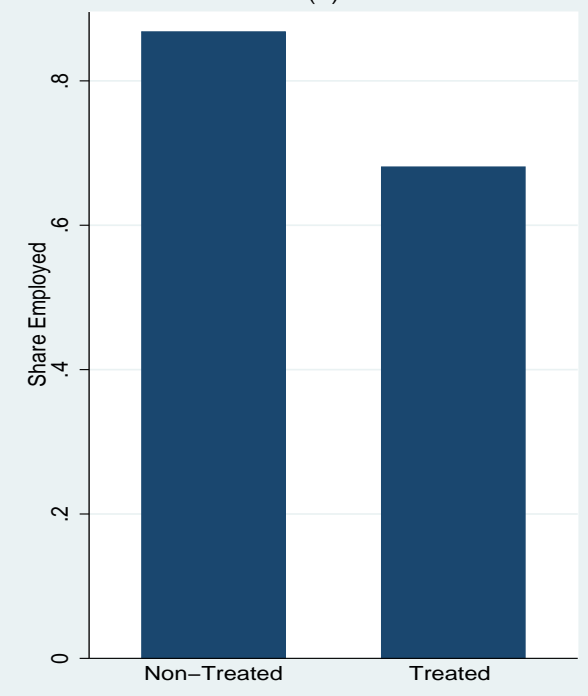

(B)

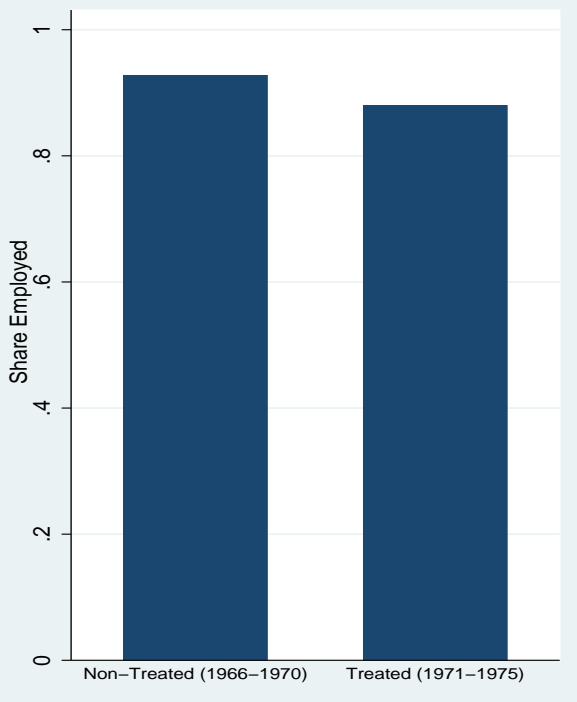

Figure 3: Employment Share for 6-5-4 and 6-3-3-4 System Participants

Table 1 presents summary statistics by treatment and control observations 
Table 1: Summary Statistics by 6-3-3-4 and Old Program Participants

\begin{tabular}{ccccccc}
\hline \hline & \multicolumn{2}{c}{ Panel A } & \multicolumn{2}{c}{ Panel B: } & \multicolumn{2}{c}{ Panel C: Those with Secondary } \\
& \multicolumn{2}{c}{ Age above 15 } & \multicolumn{2}{c}{ Those born 1966-1975 } & \multicolumn{2}{c}{ qualification born 1966-1975 } \\
& $6-5-4$ & $6-3-3-4$ & $6-5-4$ & Treated & $6-5-4$ & Treated \\
\hline Year of School & 4.930 & 8.472 & 6.50 & 6.98 & 12.405 & 12.534 \\
& $(5.840)$ & $(5.650)$ & $(6.104)$ & $(5.894)$ & $(1.351)$ & $(1.386)$ \\
Employed & 0.837 & 0.59 & 0.885 & 0.864 & 0.927 & 0.880 \\
& $(0.370)$ & $(0.492)$ & $(0.319)$ & $(0.343)$ & $(0.260)$ & $(0.326)$ \\
Per capita & 82352.08 & 85154.58 & 82216.56 & 81082.72 & 102166.4 & 96360.73 \\
expenditure & $(94806.64)$ & $(86723.16)$ & $(83132.76)$ & $(89678.88)$ & $(87679.71)$ & $(78370.12)$ \\
Female & 0.483 & 0.552 & 0.558 & 0.571 & 0.367 & 0.460 \\
& $(0.499)$ & $(0.497)$ & $(0.498)$ & $(0.495)$ & $(0.483)$ & $(0.499)$ \\
Household Size & 6.267 & 7.001 & 7.13 & 6.95 & 6.23 & 6.136 \\
& $(3.364)$ & $(3.438)$ & $(3.345)$ & $(3.253)$ & $(2.765)$ & $(2.852)$ \\
Age & 54.47 & 25.75 & 41.01 & 36.41 & 41.165 & 36.49 \\
& $(12.152)$ & $(6.887)$ & $(1.535)$ & $(1.616)$ & $(1.904)$ & $(1.5207)$ \\
Wage & 38844.76 & 28766.09 & 31456.09 & 42177.93 & 37472.24 & 50318.79 \\
& $(288590.1)$ & $(156143.4)$ & $(69090.81)$ & $(235536.1)$ & $(98743.29)$ & $(187559.2)$ \\
Urban & 0.298 & 0.320 & 0.291 & 0.288 & 0.444 & 0.441 \\
& $(0.457)$ & $(0.466)$ & $(0.454)$ & $(0.453)$ & $(0.498)$ & $(0.497)$ \\
Christian & 0.550 & 0.539 & 0.494 & 0.502 & 0.685 & 0.704 \\
& $(0.498)$ & $(0.498)$ & $(0.500)$ & $(0.500)$ & $(0.465)$ & $(0.457)$ \\
Married & 0.818 & 0.463 & 0.900 & 0.884 & 0.911 & 0.812 \\
& $(0.386)$ & $(0.499)$ & $(0.300)$ & $(0.320)$ & $(0.285)$ & $(0.392)$ \\
N & 5916 & 8862 & 1302 & 1397 & 248 & 324 \\
\hline \hline
\end{tabular}

Note: The sample size differs on some of the variables considered like Wage.

for some key variables used in our analysis. Panel A summarizes results for the whole sample used in our econometric analysis. Panel B summarises results for the most relevant age cohort for analysis. Those born close to the first treated sample. Panel $\mathrm{C}$ summarizes results for those whose highest qualification is at the secondary level and in the most relevant age cohort. Some of the differences between the treated and control sample are expected given exposure to treatment depends on year of birth. For most of the variables highlighted not correlated with age, we see similarities in means between the treated and the control sample. This 
similarity is more evident in panel $\mathrm{B}$ and $\mathrm{C}$ which has a sample of individuals closer in age and more similar. For example for column (6), all the variables apart from years of schooling and age are not statistically different for the treated and control sample. In contrast for panel $\mathrm{C}$ years of schooling for the control and treatment group are not statistically different. However share female, share married and share employed are statistically different. We are interested in potential effects of treatment on employment, wages and PCE. The results of our test of statistical difference in mean wages, PCE and share employed do not suggest any difference between the treated and control sample in the samples highlighted in panel B but we find significant difference in PCE and share employed in Panel A. In contrast in Panel C, we find significant difference in the share employed but no difference in mean wages or PCE. This simple comparisons of means suggest that despite the fact that the treated are younger than the control group, they are fairing no worse on average in terms of wages and PCE. Furthermore, while Table 1 suggests that the treated are less likely to be employed than the control group, this lower employment may not be linked with program exposure but as explained above, the rapid increase in population growth for younger cohorts might explain the lower share employed for the treated sample. This would be the case if growth in employment opportunities does not keep pace with growth in population. Table 2 highlights the estimates of the Foster-Greer-Thorbecke (FGT) class of poverty indices $p_{0}$ to $p_{2}$ (see Foster, Greer, and Thorbecke et al 1984), as well as estimates of the standard deviation of these indices. We present these indices by treatment status. In panel A the estimates of these indices using the full sample above 15 is summarized while in Panel B the estimates using the sample born 1966-1975 is summarized. In panel $\mathrm{C}$ the estimates for the most relevant sub-sample were effects should be most likely discernable as described above is summarized. To estimate these indices we make use of the $\$ 1$ per day poverty line (DPDPL). Notice 


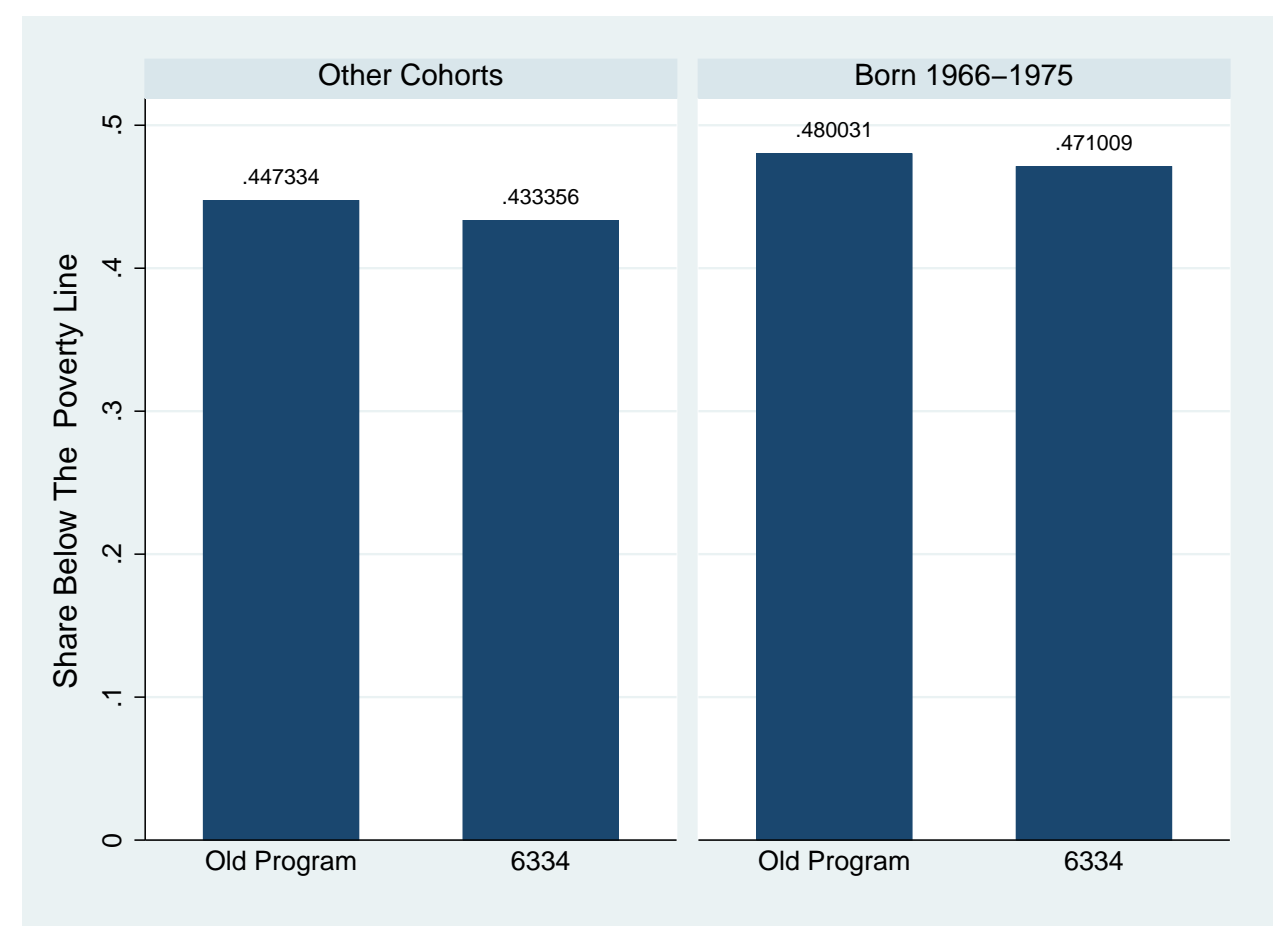

Figure 4: Head Count Measures of Poverty by Treatment Status

in all three panels that the share below the poverty line is lower for the treated group than the control group which may be suggestive of some welfare effects of the system change. This lower head count ratio or poverty incidence result is also illustrated in Figure 3. For example, when the head count ratio is estimated using the relevant sample of those born 1966-1975, we notice that about $48 \%$ of people who passed through the 6-5-4 program are poor in contrast to just $47 \%$ of those who passed through the treatment (6-3-3-4). In contrast if we look solely at those with a secondary qualification within the same cohort, we find that $36 \%$ of the control group are poor in contrast only $31 \%$ of the treated group are poor. Table 2 also highlights the poverty-gap measure $P_{1}$ and the squared poverty-gap indices $P_{2}$ which captures the severity of poverty. Notice again similar trends in the 
poverty gap and poverty severity indices as with $P_{0}$ when comparing the treated and control samples. The results for the most part suggest a lower poverty gap ratio for participants of the treatment system versus the old system. Similarly, estimates in panel $\mathrm{A}$ and $\mathrm{C}$ suggest that the severity of poverty is on average higher for participants in the old system than the 6-3-3-4 system.

Table 2: FGT Poverty Measures Estimation by Program Type

\begin{tabular}{ccccccc}
\hline \hline & \multicolumn{2}{c}{ Panel A } & Panel B: Birth Cohort & \multicolumn{2}{c}{ Panel C: Born 1966-1975 } \\
& Age $>15$ & \multicolumn{2}{c}{ 1966-1975 } & \multicolumn{2}{c}{ Secondary Qualification } \\
& Old Program & $6-3-3-4$ & Old Program & $6-3-3-4$ & Old Program & $6-3-3-4$ \\
Head Count Ratio & 0.455 & 0.439 & 0.480 & 0.471 & 0.359 & 0.312 \\
$\left(P_{0}\right)$ & $(0.498)$ & $(0.496)$ & $(0.500)$ & $(0.500)$ & $(0.481)$ & $(0.464)$ \\
Poverty Gap & 0.186 & 0.175 & 0.191 & 0.192 & 0.122 & 0.112 \\
$P_{1}$ & $(0.261)$ & $(0.255)$ & $(0.264)$ & $(0.266)$ & $(0.215)$ & $(0.216)$ \\
Poverty Severity & 0.102 & 0.096 & 0.106 & 0.107 & 0.061 & 0.059 \\
$P_{2}$ & $(0.186)$ & $(0.181)$ & $(0.193)$ & $(0.195)$ & $(0.143)$ & $(0.155)$ \\
$\mathrm{N}$ & 5916 & 8862 & 1302 & 1397 & 248 & 324 \\
\hline \hline
\end{tabular}

What can we infer from these descriptive analysis? First there is some prima facie evidence that those who were exposed to the 6-3-3-4 system on average might be less likely to the poor and have a lower poverty gap and severity. However these improvements may not be substantial given the similarity in these indices for both groups. Moreover, mean wages for the treated group though higher than the control group in the relevant cohort, is not statistically different. Second, even though the treated are on average less likely to be poor, they are less likely to be employed than those who passed through the 6-5-4 system. It is important to mention that the descriptive analysis highlighted above only provides evidence of differences between the treated and control sample analysed. It cannot be used to detect any causal effect of the program. However noting that the treated sample is not fairing worse on typical welfare indicators is encouraging. Next we turn to 
our econometric analysis to identify potential system effects.

\section{Empirical Strategy}

\subsection{Identification and Estimation}

In this paper we focus on two questions. First does exposure to the 6-3-3-4 education system lead to welfare improvement for participants compared to 6-5-4 participants? Second, do individuals who passed through the 6-3-3-4 have a higher probability of being employed than their counterparts who passed through the 65-4 system? To answer these questions we make use of a regression discontinuity (RD) design. RD analysis is an intuitively appealing, rigorous nonexperimental approach first suggested by Thistlewaite and Campbell (1960). It is used to evaluate causal effects of interventions. Typical scenarios that fit the RD approach involve assignment to treatment based on a score at or above a certain cut-off. The $\mathrm{RD}$ approach has been used to identify causal impacts in several papers including Angrist and Lavy, (1999), Jacob and Lefgren, (2006); McEwan and Shapiro, (2008); Matsudaira, (2008); and Lemieux and Milligan, (2004).

For the first question focused on welfare, a probit model controlling for widely accepted correlates of poverty as in equation 1 provides a starting point.

$$
\operatorname{Prob}(P=1 \mid X)=\Phi\left(\alpha_{0}++\alpha_{1} T_{i}+X_{i} \alpha_{2}+\varepsilon_{i}\right) i=1, \ldots ., N
$$

The dependent variable in this case is a binary indicator which takes on a value of 1 if an individual is poor and takes a value of 0 otherwise. By poor we mean individuals with per capita consumption expenditure at or below a pre-determined poverty line. In equation $1, X_{i}$ are our control variables that affect the probability an individual is poor. Included here are control variables that could affect the probability of being poor. Our T variable is a dummy which takes a value of one if an individual experienced the treatment while individuals who went through the 
old system are assigned a $0 . \Phi($.$) in equation (1) indicates the standard normal$ distribution. This probit model can also be used to check the effect of treatment on the likelihood of being employed. In this case the dependent variable takes on a value of 1 if an individual is employed and takes a value of 0 otherwise. $\varepsilon_{i}$ is the independent error term and is distributed $N(0, \sigma)$. Treatment as defined above is based on year of birth. Those born 1971 and later should pass through the treatment (6-3-3-4 system). In contrast, those born before 1971 should pass through the 6-5-4 system (control).

Poverty status is just one potential way of measuring welfare improvements from treatment. Other measures or indicators are poverty severity, poverty gap, per capita expenditure and wages. To estimate possible effects of treatment on each of these other indicators, a linear model similar to equation 1 with respect to control variables, can also be estimated using Ordinary Least Squares (OLS) as a starting point. Equation 2 depicts this simple model.

$$
Y_{i}=\beta_{0}+\beta_{1} T_{i}+X_{i} \beta_{2}+\varepsilon_{i}
$$

Here $Y_{i}$ is the welfare outcome of interest which could be poverty gap; poverty severity; wages or $\mathrm{PCE}$, and $\mathrm{X}$ is a vector of control variables.

In equation 1 and $2, \alpha_{1}$ and $\beta_{1}$ represents the effect of being exposed to treatment. If $\operatorname{Cov}\left(T_{i}, \varepsilon_{i}\right) \neq 0$ then the probit estimate of $\hat{\alpha_{1}} \neq \alpha_{1}$. Similarly our OLS estimate $\beta_{1}^{O L S} \neq \beta_{1}$. Bias in the estimate of $\alpha_{1}$ and $\beta_{1}$ is possible because the treated sample is younger than the control sample and given standard trends in the age earning profile, the treated sample on average will have less experience leading to lower wages or higher probability of being poor. Similarly being younger would mean the treated group will complete their school to work transition later than the control group which may lead to an observed lower likelihood of being employed. 
To mitigate this potential challenge and derive unbiased estimates of treatment effects, we make use of a sharp regression discontinuity $(\mathrm{RD})$ design. Specifically for each individual i, a random variable $Y_{i}$ represents the outcome of interest ${ }^{10}$ while the scalar regressor $x_{i}$ is the running variable that determines treatment assignment based on a cutoff. In our case, year of birth is the running variable and cutoff occurs at 1971. We estimate local average treatment effects (LATE) exploiting exogenous variation in system participation based on year of birth. In our implementation of the sharp $\mathrm{RD}$ design, we assume the probability of treatment changes somewhat deterministically from zero to one at the 1971 year of birth cutoff. Students born from 1971 onwards were exposed to the treatment while those born before 1971 typically would be exposed to the previous system (6-5-4). We focus on large-sample inference for the average treatment effect at the cutoff (which we define as $c$ ). Meaning that identification of the effect of exposure to 6-3-3-4 is based on comparing the outcomes of treated students born in 1971 and just to the right of this cutoff, with those of students born just to the left of the 1971 cutoff. Given the program was initiated in 1982 when those born in 1971 were about to enter secondary school, the year of birth which is the basis of the cutoff cannot be manipulated. Hence year of birth near cutoff should not introduce sharp differences in unobserved variables that affects an individual's economic welfare. This allows us to deduce causal interpretation related to treatment for this subpopulation. ${ }^{11}$ It is important to note that our estimates are the average effect for a subpopulation with covariate value close to $x_{i}=c$. This method of identification is similar to a local randomized experiment. One limitation of the RD method is its limited degree of external validity. With this method, we cannot

\footnotetext{
${ }^{10}$ In our case we have multiple outcomes of interest including poverty status, employment status and wages.

${ }^{11}$ Meaning we are able to achieve internal validity.
} 
estimate the overall average effect of the 6-3-3-4 system.

\subsection{RD Implementation Challenges}

The challenge in the implementation of the sharp RD design in our case is the small potential for wrong assignment. This occurs typically with delayed enrollment or grade repetition. For example an individual born in 1970 with our method of assignment would be classed as passing through the 6-5-4 system. However if this student repeated 3rd grade they would enter secondary school at the same time as those born in 1971 and would have been treated. We do not worry too much about this possible misassignment since grade repetition is not common in Nigeria and in a large sample would not be able to drive results. As noted above about $4.5 \%$ of students in our sample have repeated a grade. This could occur at the primary or secondary level hence the chance that we get individuals in our sub-sample who repeated a grade at a time when it would lead to misassignment to the control group is slim. Another possible concerning confounding factor is delayed or early enrollment. If a child delayed enrollment to primary 1, then they also could be exposed to treatment even though born before $1971 .^{12}$ We provide ways of testing for program effects taking into accounting this possible confounding factor in program assignment close to the 1971 cutoff. Specifically we use information in the survey on when individuals started school. Hence as a robustness check, we implement the RD approach dropping students who started school after 8 years and reassigning to treatment those who were born in 1970 and 1969 and started school late enough to experience treatment. We refer to this sample as the restricted sample later on in the results section. ${ }^{13}$.

\footnotetext{
${ }^{12}$ It is also possible for a child to start primary school early before age 5 but this is not common so we do not worry about this.

${ }^{13} \mathrm{It}$ is important to note that not everyone answered this question so it is possible a negligible number of individuals started school late and remain in the sample misassigned even in the restricted sample.
} 
Another potential issue that could invalidate our RD design is if there is an unobserved variable that is correlated with treatment and also welfare. One possible factor that one may needs to worry about especially given the significant changes in economic conditions in Nigeria over time is economic/labor market conditions upon graduation. If the distribution of labor market/economic conditions faced by individuals when they graduated on average differ across treatment and control group around the cutoff used in the RD estimation then our local average treatment effect (LATE) may be biased. This is because such labor market conditions potentially have long term effects on individual's labor market outcomes and welfare, independent of treatment. To check for possible issues with economic condition upon graduation, we obtain constant Gross Domestic Product per Capita (GDPC) data for Nigeria from the World Bank from 1960-2010. We then compute GDP per capita growth rates and find the mean GDPC for the sample close to the 1971 cutoff at high school graduation (about age 18) ${ }^{14}$ Our computed mean GDPC for the treated and control group for the whole sample and around the cutoffs are not statistically different. Meaning on average participants of both programs faced similar economic growth conditions at age 18 .

Another potential confounding factor that may be relevant to a subset of the sample is the timing of the inception of universal primary education (UPE) in some parts of Nigeria. Osilli and Long (2008) and Uwaifo Oyelere (2010) discuss this free primary education program in detail. While the Eastern and Western parts of Nigeria were exposed to free education before 1976, all the Northern regions were exposed to free primary education for the first time in 1976. Coincidentally 1976 is the year when the first set of those in the treatment sample begin primary school. Since free education can stimulate school enrollment and higher attainment

\footnotetext{
${ }^{14}$ We pick economic conditions at high school graduation/age 18 because the bulk of individual in Nigeria enter the labor market on or before this time.
} 
which can have effects on welfare over the long-run, then for a part of the sample around the cutoff, there exists a difference in exposure to free education at school entrance age for treatment and control group. We do not worry to much about this potential confounding factor because this issue is only a source of concern for our estimated effects using the whole sample because it induces differences in the likelihood of enrollment in school for a small sub-sample in the control and treatment group. However when we restrict the sample to those whose highest qualification is at the secondary level, which is our most relevant sample, this issue is irrelevant because for both treatment and control group the sample is restricted to individuals who attended school. Since these individual attended school, there is no difference in the likelihood of school enrollment around the cutoff for this subgroup as this probability is equal to 1 for participants in both the old and the 6-3-3-4 system.

\subsection{RD Estimation Implementation}

To provide evidence of the impact of 6-3-3-4 using sharp RD design, we estimate LATE using a local polynomial nonparametric RD treatment-effect point estimator. Specifically, we following the approach proposed in Calonico, Cattaneo, and Titiunik (2014b). ${ }^{15}$ One advantage of this approach is that it allows us derive robust statistical inference. ${ }^{16}$ We implement this approach in STATA using the command rdrobust provided by CCT(2014a). Using this command, treatment effects are derived using a local linear estimator with a local quadratic bias correction and a triangular kernel. Variance estimators employed in the estimation are those proposed in CCT(2014a) and are computed using three nearest neighbors. One of the many benefit of using the rdrobust command for estimating treatment

\footnotetext{
${ }^{15}$ Hereon CCT.

${ }^{16}$ In particular, the bias-corrected inference procedure proposed in $\mathrm{CCT}(2014 \mathrm{~b})$ is robust to large bandwidth choices.
} 
effects in a sharp RD is that robust bias-corrected confidence intervals (CIs) for the average treatment effects at the cutoff can be easily computed.

Figure 5 captures the $\mathrm{RD}$ plots for the different measures of poverty we consider in our analysis while Figure 6 captures plots for wages and share employed. To construct these plots, we make use of the rdplot command provided by CCT (2014b). Employing a nonparametric partitioning estimator, RD plots are constructed using evenly spaced binned sample means that trace out the underlying regression function. The number of bins for the RD estimate plot is obtaining using the integrated mean squared-error (IMSE)-optimal evenly spaced method using spacing estimators (see CCT, 2014b).

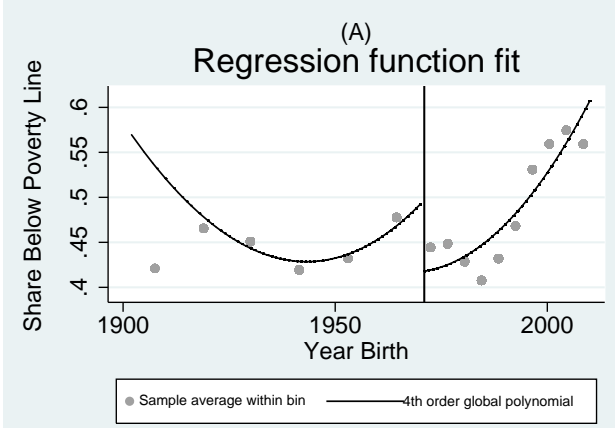

(B)

Regression function fit

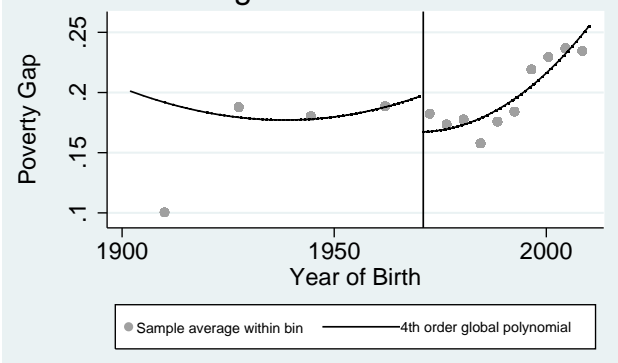

(C)

Regression function fit

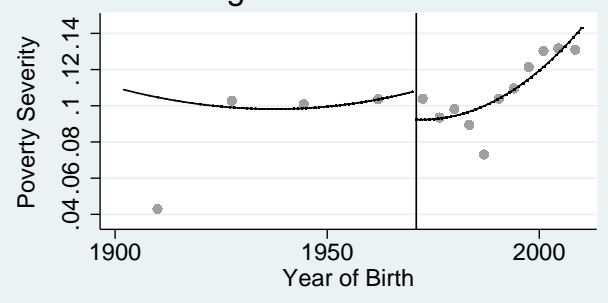

sSample average within bin $\longrightarrow$ th order global polynomial

Figure 5: RD Plots: Poverty Measures by Treatment Status

Figure 5a shows RD poverty status plots using the dollar per day (DPD) 
measure. Figure 5b shows the RD poverty gap plot and Figure 5c shows the RD poverty severity plot. We also construct $\mathrm{RD}$ plots for wages and share employed (see Figure $6 \mathrm{a}$ and $6 \mathrm{~b}$ ). Figure 5a provides evidence of a discontinuity at year 1971 while Figure 5b and 5c provide less clear evidence. Similarly, while Figure 6a shows a discontinuity at the 1971 cutoff, the gap is somewhat less clear than the discontinuity for employment in figure 6b. However one observations from these plots is that given the gap at the cutoff is not large, we cannot conclude that significant treatment effects exist without estimation.

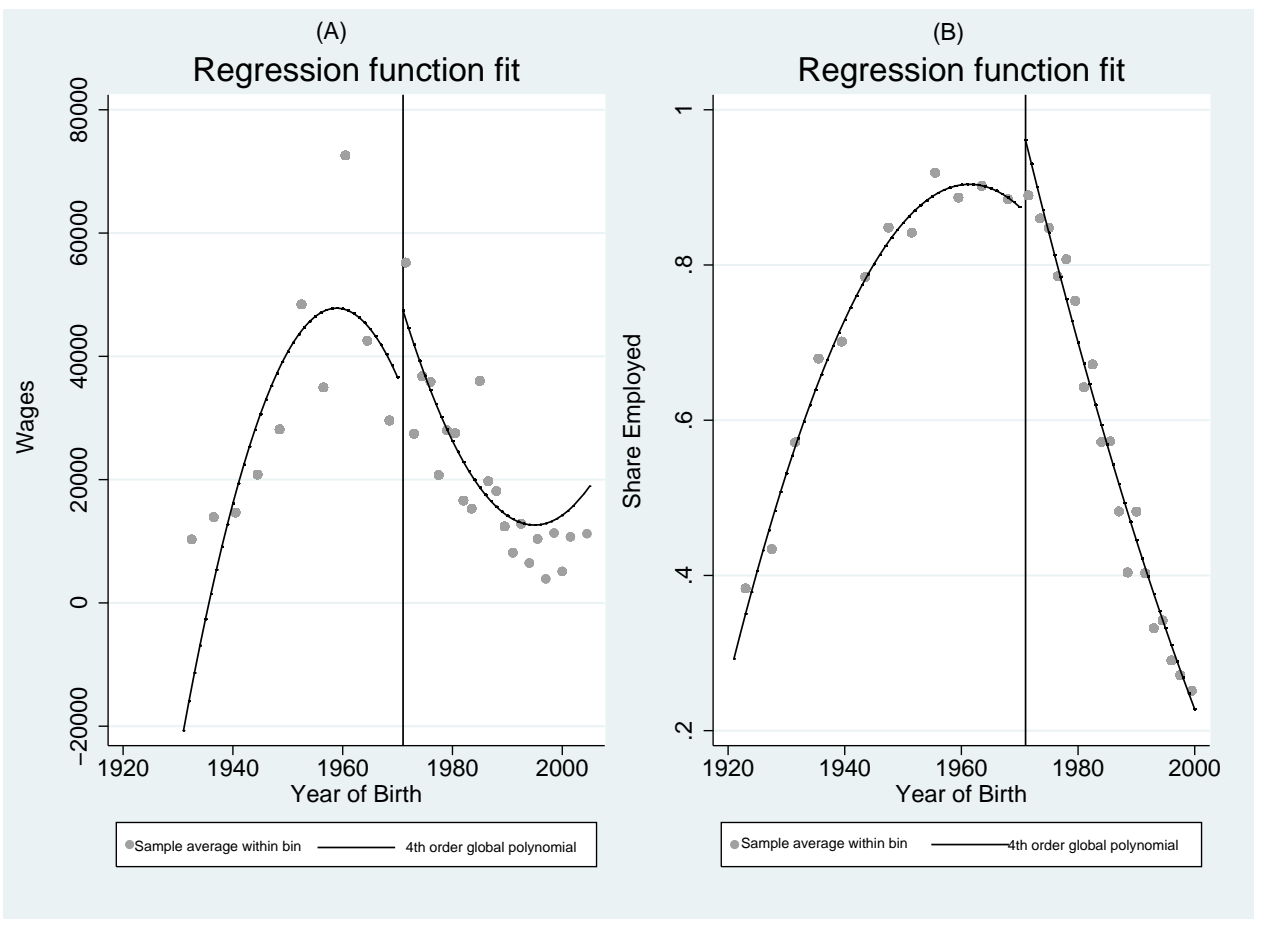

Figure 6: RD Plots: Wages and Employment by Treatment Status

We also construct RD plots for the sample where treatment effects should be most discernable (individuals whose highest qualification is at the secondary level). Figure (7a) shows the discontinuity for poverty status while Figure (7b) shows the 
discontinuity for wages and Figure (7c) depicts the RD plot for share employed. Notice that the discontinuity is clearer for wages and poverty status in these figures (7a and $7 \mathrm{~b})$ compared to similar plots for the whole sample presented in Figures (5a) and (6a). For employment there does not appear a clear discontinuity at the cutoff in Figure (7c) and the discontinuity appears more apparent in Figure (6b) for the general population than in the sub-sample. Finding bigger gaps at the cutoff for this sub-sample in wages and poverty status is consistent with the likelihood of finding discernable impacts of the system for individuals whose highest qualification is at the secondary level compared to the general sample.

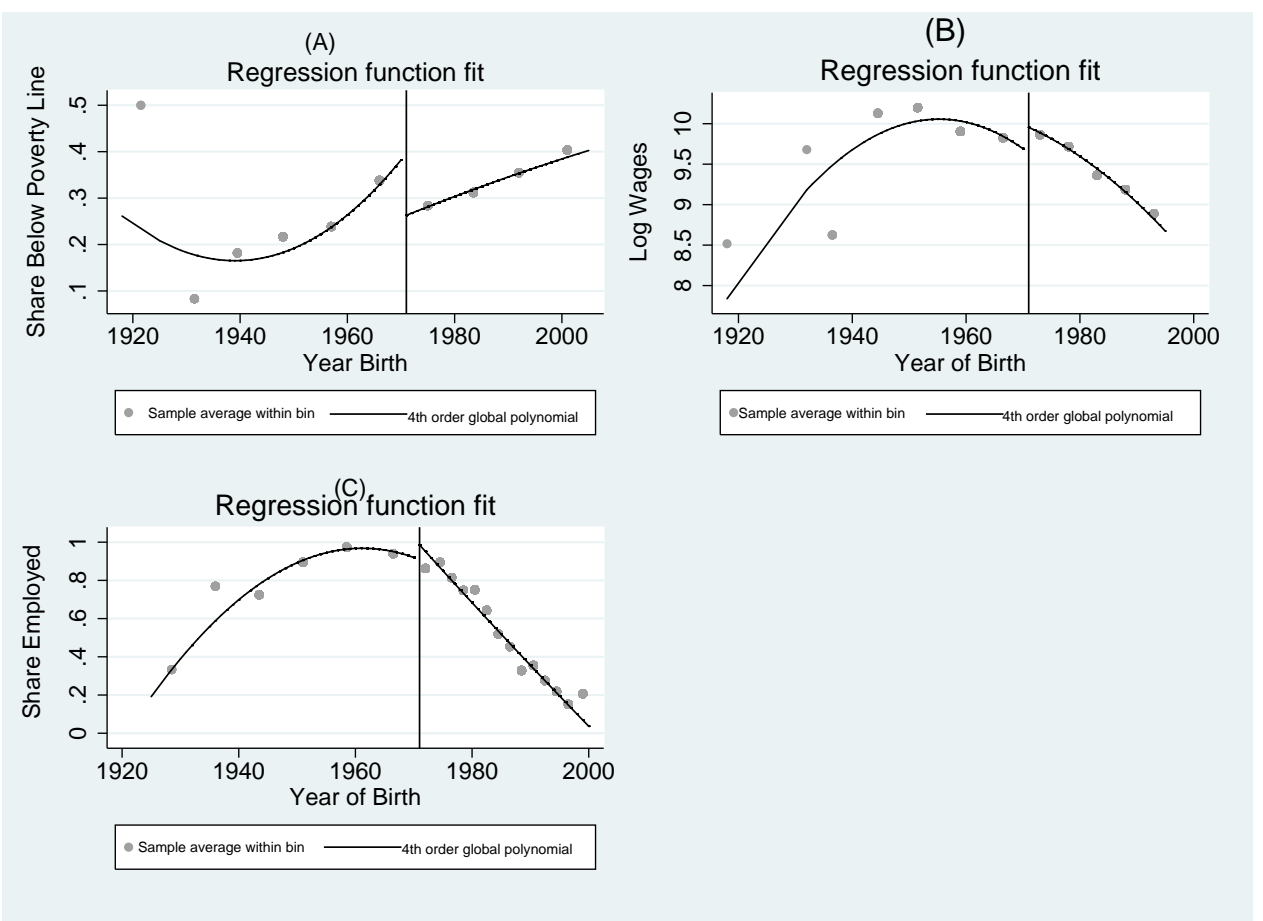

Figure 7: RD Plots: Wages and Employment by Treatment Status 


\subsection{Confidence Intervals and Bandwidth Selection}

One benefit of using the rdrobust command of CCT (2014) for estimating treatment effects in a sharp RD is that robust bias-corrected confidence intervals (CI) for the average treatment effects at the cutoff can be easily computed. This is important because typically in practice, confidence intervals are constructed assuming away potential bias of the estimator. However, as CCT (2014) note, making such an assumption is only justifiable if the smoothing leading bias of the $\mathrm{RD}$ estimator is small which requires choosing a smaller bandwidth than the Mean Square Error (MSE)-optimal one. In empirical research this choice is typically not made and the potential effect of the leading bias on the performance of confidence intervals is ignored.

In our estimation using the rdrobust command, the conventional CIs described above are presented alongside two other alternative approaches to constructing confidence intervals. The first of these approaches commonly employed in the nonparametric literature uses bias correction. The problem with the bias correction approach for constructing CIs is that it has poor finite-sample properties making it less preferable for empirical research. The second alternative approach was proposed by CCT (2014b) and produces robust CIs. The difference with this latter approach and the bias corrected CI is the use of a different variance estimator(see CCT (2014) for details). The advantage of this approach is that it offer superior finite sample performance and allows for the use of MSE-optimal bandwidth choices.

In summary, we derive using CCT (2014) estimated effects of treatment using two point estimators and three CIs. The first estimated effect is derived using a linear local polynomial estimator and conventional CIs are estimated. The second, estimated effect is derived using a linear local polynomial with a 2nd order local 
polynomial bias correction and bias corrected CIs are estimated. The last estimate is derived using the second estimator but the robust bias corrected CIs suggest by CCT (2014) highlighted above. Our inference will be derived using the biascorrected estimator alongside the robust bias corrected CI. ${ }^{17}$

We derive the LATE of system participation following the RD procedure highlighted above first using the main sample, and then the restricted sample. To recap, this restricted sample drops those who start school after 8 (these individuals are typically different) and in this sample we correct for those who get misassigned to the control group because of late school enrollment. As we noted above, given the significant changes with the 6-3-3-4 system compared to the prior system were at the secondary level, we also derive estimates restricting the sample to the sub-sample whose highest qualification is at the secondary level. As noted above, this is the sample where treatment effect should be most noticeable. In this sample, those with tertiary education, just primary education and secondary without any qualification get dropped. We also estimate LATE on the aforemention secondary sub-sample, adding on the conditions imposed in the restricted sample. We also conduct some robustness checks using other sub-samples. The challenge with many of the sub-sample analysis is that the sample size becomes small which makes it more difficult to identify effects and deduce inference correctly. For example when the sample size is small, estimated standard errors are large and finding insignificant estimates is likely. In the next section we present the LATE estimates across different measures of welfare and provide inferences.

\footnotetext{
${ }^{17}$ The robust bias corrected CI is calculated using the variance estimator suggested by CCT
} 


\section{Results}

Table 3 presents the estimates of the treatment effect using the rdrobust command as described above. column (1) summarizes the results for poverty status based on a dollar per a day (DPD) poverty line. This line is used to demarcate absolute/extreme poverty and is our preferred poverty line. Column (2) summarizes the results for poverty gap based on the aforementioned poverty line and column (3) summarizes the results for poverty severity using DPD. Columns (4)-(6) are similar to columns (1)-(3) but a higher poverty line is employed. This line is called the Relative Poverty line (RPL) in Nigeria and is set at N66,802.20 in the year of the survey(about a dollar and twenty five cents). While the DPD poverty line identifies the extreme poor. This line general separates the poor from the non-poor in the Nigerian context.

As discussed about estimates using the three methods (conventional, bias corrected and robust) are presented. The results in Table 3 suggest that those exposed to the treatment (6-3-3-4) had about a $6.7 \%$ lower probability of being in extreme poverty. Focusing on the robust method, exposure does not appear to reduce the severity of poverty. We also find some evidence that exposure leads to a smaller poverty gap when we consider the RPL. This result is consistent with finding a significant effect on poverty status using the more conservative absolute poverty line (DPD).

Table 4 panel A presents the results using the restricted sample as defined above. In Panel B we present results for a sample dropping all those who begin school after 6 years. The restriction on the sample in panel B has pros and cons. First, it might be useful to drop those who delayed entry to school because they be different from others and on average exhibit lower welfare outcomes regardless of treatment. However, starting school late is common in the rural areas in the past 
Table 3: Are individuals who passed through the 6-3-3-4 system less likely to be poor? Estimates using RD

\begin{tabular}{|c|c|c|c|c|c|c|}
\hline Method & $\begin{array}{c}\text { Poverty } \\
\text { Status } \\
(1)\end{array}$ & $\begin{array}{l}\text { Poverty } \\
\text { Gap } \\
(2)\end{array}$ & $\begin{array}{c}\text { Poverty } \\
\text { Severity } \\
(3)\end{array}$ & $\begin{array}{c}\text { RPL Poverty } \\
\text { Status } \\
(4)\end{array}$ & $\begin{array}{c}\text { RPL Poverty } \\
\text { Gap } \\
(5)\end{array}$ & $\begin{array}{c}\text { RPL Poverty } \\
\text { Severity } \\
(6)\end{array}$ \\
\hline Conventional & $\begin{array}{c}-0.059^{* *} \\
(0.029)\end{array}$ & $\begin{array}{c}-0.022 \\
(0.015)\end{array}$ & $\begin{array}{l}-0.008 \\
(0.010)\end{array}$ & $\begin{array}{l}-0.032 \\
(0.028)\end{array}$ & $\begin{array}{l}-0.027^{*} \\
(0.016)\end{array}$ & $\begin{array}{l}-0.014 \\
(0.012)\end{array}$ \\
\hline Bias-corrected & $\begin{array}{c}-0.067^{* *} \\
(0.029)\end{array}$ & $\begin{array}{c}-0.025^{*} \\
(0.015)\end{array}$ & $\begin{array}{l}-0.007 \\
(0.010)\end{array}$ & $\begin{array}{l}-0.038 \\
(0.028)\end{array}$ & $\begin{array}{c}-0.032^{*} \\
(0.016)\end{array}$ & $\begin{array}{l}-0.016 \\
(0.012)\end{array}$ \\
\hline Robust & $\begin{array}{c}-0.067^{* *} \\
(0.034)\end{array}$ & $\begin{array}{l}-0.025 \\
(0.017)\end{array}$ & $\begin{array}{l}-0.007 \\
(0.012)\end{array}$ & $\begin{array}{l}-0.038 \\
(0.033)\end{array}$ & $\begin{array}{l}-0.032^{*} \\
(0.019)\end{array}$ & $\begin{array}{l}-0.016 \\
(0.014)\end{array}$ \\
\hline Observations & 5,145 & 5,409 & 7,225 & 5,409 & 5,145 & 6,340 \\
\hline
\end{tabular}

Note: In columns (1)-(3) estimates based on $\$ 1$ per day poverty line.

and dropping these observations which are substantial could lead to estimates that may not be valid for the sub population we are interested in. The results in Panel A suggest that in the restricted sample, on average exposure to treatment does not seem to reduce poverty likelihood, poverty gap and poverty severity in most specifications. While we find treatment reduces the probability of being extremely poor using the second method (bias corrected), this is not our preferred method given its limitations in small samples. In contrast in when we drop all students who enrolled late in school (panel B), we find significant treatment effects. Notice the significant reduction in the sample over which the estimates are derived when we drop those who enroll late. The results in panel B suggest that treatment leads to a $9.8 \%$ reduction in the probability of being poor and also reduces the poverty gap using both poverty lines and poverty severity using the RPL. The contrast in estimates in panel A and B may suggest that on average student who begin school after 6 may be different. 
Table 4: Does the 6-3-3-4 system Reduce Poverty Risk? RD estimates with Restricted Samples

\begin{tabular}{lcccccc}
\hline \multirow{2}{*}{ Method } & $(1)$ & $(2)$ & $(3)$ & $(4)$ & $(5)$ & $(6)$ \\
& $\begin{array}{c}\text { Poverty } \\
\text { Status }\end{array}$ & $\begin{array}{c}\text { Poverty } \\
\text { Gap }\end{array}$ & $\begin{array}{c}\text { Poverty } \\
\text { Severity }\end{array}$ & $\begin{array}{c}\text { RPL Poverty } \\
\text { Status }\end{array}$ & $\begin{array}{c}\text { RPL Poverty } \\
\text { Gap }\end{array}$ & $\begin{array}{c}\text { RPL Poverty } \\
\text { Severity }\end{array}$ \\
\hline \hline \multirow{3}{*}{ Conventional } & -0.048 & -0.011 & -0.005 & -0.026 & -0.020 & -0.008 \\
& $(0.030)$ & $(0.015)$ & $(0.011)$ & $(0.030)$ & $(0.017)$ & $(0.012)$ \\
Bias-corrected & $-0.055^{*}$ & -0.012 & -0.004 & -0.031 & -0.023 & -0.008 \\
& $(0.030)$ & $(0.015)$ & $(0.011)$ & $(0.030)$ & $(0.017)$ & $(0.012)$ \\
Robust & -0.055 & -0.012 & -0.004 & -0.031 & -0.023 & -0.008 \\
Observations & $(0.035)$ & $(0.017)$ & $(0.012)$ & $(0.035)$ & $(0.020)$ & $(0.014)$ \\
\hline \multirow{3}{*}{ Conventional } & 4,927 & 6,161 & 6,161 & 4,927 & 4,927 & 6,161 \\
\hline \multirow{5}{*}{ Bias-corrected } & $-0.085^{* *}$ & $-0.036^{*}$ & -0.020 & -0.039 & $-0.040^{*}$ & $-0.027^{*}$ \\
& $(0.039)$ & $(0.018)$ & $(0.013)$ & $(0.036)$ & $(0.021)$ & $(0.015)$ \\
Robust & $-0.098^{* *}$ & $-0.040^{* *}$ & $-0.023^{*}$ & -0.048 & $-0.045^{* *}$ & $-0.031^{* *}$ \\
& $(0.039)$ & $(0.018)$ & $(0.013)$ & $(0.036)$ & $(0.021)$ & $(0.015)$ \\
Observations & $-0.098^{* *}$ & $-0.040^{*}$ & -0.023 & -0.048 & $-0.045^{*}$ & $-0.031^{*}$ \\
\hline \hline
\end{tabular}

Standard errors in parentheses

*** $\mathrm{p}<0.01,{ }^{*} * \mathrm{p}<0.05,{ }^{*} \mathrm{p}<0.1$

In columns (1)-(3) estimates are based on $\$ 1$ per day poverty line.

Table 5 highlights our other potential measures of welfare (wages, PCE and employment). The first three columns summarize the results for the full sample while the last three columns summarize the results for the restricted sample as described above. Given only a small sample earn wages, the sample size for this analysis is much smaller than the samples we employ in estimating effects for other measures of welfare we consider. Panel A summarizes treatment effects for wages, per capita expenditure and employment. While Panel B focus on estimates using $\log$ wages and $\log$ PCE. These results provide no evidence that treatment affects wages or PCE on average using our preferred method. Even when we use log wages 
and PCE, we only see significant treatment effects when we use the bias corrected method. In contrast, our results suggest significant effects on employment. Those exposed to the treatment are $5.3 \%$ more likely to be employed than the control group. If we exclude all those who begin school after 6 years as we did in Panel B of Table 5, we find no evidence of treatment affecting wages, PCE or employment probability. ${ }^{18}$ This is in contrast to finding significant effects of treatment on poverty measures in the sub-sample where late enrollers are dropped.

Table 6 presents the results for the sample we expect to see discernable effects. This is the sample focused solely on individuals whose highest qualification is at the secondary level. Panel A focuses on the full sample of these individuals while Panel B focuses on a sub-sample of these individuals who satisfy the conditions for the restricted sample. We find negative treatment effects using our robust method for poverty incidence. As expected the magnitude of the effects are greater in this sub-sample than the full sample. Specifically we find that treatment leads to a decrease in the probability of being poor by $13.8 \%$. We do not find significant effects for poverty severity or poverty gap. When we look at the restricted sample we do not find any significant effects using any method just as in Table 4 Panel A. Given the possibility that this sample may have some bias, we drop all those with secondary qualifications who enroll after 6 years (results not presented) and estimates similar to those in Panel A are noted. However, for poverty incidence based on DPD, we find significant effects of treatment using the conventional and bias corrected methods but not our preferred robust method. The small sample size in this analysis might explain this lack of significance using our preferred method. The significant difference in estimates for the sample summarised in Panel B compared to A and the sample where individuals who enroll late are dropped, suggests potential selectivity issues with individuals who start school

\footnotetext{
${ }^{18}$ Results not shown but available on request.
} 
late. These individuals may be less motivated, lower achiever or poor which can affect welfare independent of treatment. It is possible that when such individuals are included in the treatment group it attenuates the probability of detecting treatment effect.

Table 5: Does the 6-3-3-4 system lead to higher wages, PCE and employment?: RD Estimates

\begin{tabular}{|c|c|c|c|c|c|c|}
\hline & \multicolumn{3}{|c|}{ Full Sample } & \multicolumn{3}{|c|}{ Restricted Sample } \\
\hline & (1) & $(2)$ & $(3)$ & $(4)$ & $(5)$ & $(6)$ \\
\hline \multicolumn{7}{|c|}{ Panel A: Wage/PCE/Employment } \\
\hline RD Method & Wages & $\mathrm{PCE}$ & Employed & Wages & PCE & Employed \\
\hline \multirow[t]{2}{*}{ Conventional } & $30,009.278$ & $4,904.775$ & $0.036^{*}$ & $21,545.100$ & $2,414.295$ & $0.047^{* *}$ \\
\hline & $(20,742.465)$ & $(4,282.854)$ & $(0.021)$ & $(16,664.699)$ & $(4,887.196)$ & $(0.022)$ \\
\hline \multirow[t]{2}{*}{ Bias-corrected } & $29,912.323$ & $4,001.712$ & $0.038^{*}$ & $21,916.606$ & $1,415.230$ & $0.053^{* *}$ \\
\hline & $(20,742.465)$ & $(4,282.854)$ & $(0.021)$ & $(16,664.699)$ & $(4,887.196)$ & $(0.022)$ \\
\hline \multirow[t]{2}{*}{ Robust } & $29,912.323$ & $4,001.712$ & 0.038 & $21,916.606$ & $1,415.230$ & $0.053^{* *}$ \\
\hline & $(24,084.316)$ & $(5,001.856)$ & $(0.025)$ & $(19,206.581)$ & $(5,494.200)$ & $(0.026)$ \\
\hline Observations & 1,739 & 7,992 & 4,189 & 1,473 & 6,153 & 3,818 \\
\hline \multicolumn{7}{|c|}{ Panel B: Log Specifications } \\
\hline Method & Log Wages & Log PCE & & Log Wages & $\log \mathrm{PC}$ & \\
\hline \multirow[t]{2}{*}{ Conventional } & 0.173 & 0.050 & & 0.050 & 0.030 & \\
\hline & $(0.133)$ & $(0.044)$ & & $(0.133)$ & $(0.048)$ & \\
\hline \multirow[t]{2}{*}{ Bias-corrected } & $0.225^{*}$ & 0.046 & & 0.099 & 0.029 & \\
\hline & $(0.133)$ & $(0.044)$ & & $(0.133)$ & $(0.048)$ & \\
\hline \multirow[t]{2}{*}{ Robust } & 0.225 & 0.046 & & 0.099 & 0.029 & \\
\hline & $(0.153)$ & $(0.052)$ & & $(0.155)$ & $(0.057)$ & \\
\hline Observations & 1,617 & 6,744 & & 1,572 & 6,153 & \\
\hline
\end{tabular}

Standard errors in parentheses

$* * * \mathrm{p}<0.01,{ }^{* *} \mathrm{p}<0.05, * \mathrm{p}<0.1$ 
Table 6: Does the 6-3-3-4 system Reduce Poverty Risk? Estimates for Secondary Sample

\begin{tabular}{|c|c|c|c|c|c|c|}
\hline Method & $\begin{array}{c}\text { DPD Poverty } \\
\text { Status } \\
\text { (1) }\end{array}$ & $\begin{array}{c}\text { DPD Poverty } \\
\text { Gap } \\
(2)\end{array}$ & $\begin{array}{c}\text { DPD Poverty } \\
\text { Severity } \\
(3)\end{array}$ & $\begin{array}{c}\text { RPL } \\
\text { Status } \\
(4)\end{array}$ & $\begin{array}{c}\text { RPL Poverty } \\
\text { Gap } \\
(5)\end{array}$ & $\begin{array}{c}\text { RPL Poverty } \\
\text { Severity } \\
(6)\end{array}$ \\
\hline & \multicolumn{6}{|c|}{ Panel A: Sample with a Secondary Certificate } \\
\hline Conventional & $\begin{array}{c}-0.130^{* *} \\
(0.055)\end{array}$ & $\begin{array}{l}-0.039 \\
(0.025)\end{array}$ & $\begin{array}{l}-0.015 \\
(0.016)\end{array}$ & $\begin{array}{l}-0.033 \\
(0.058)\end{array}$ & $\begin{array}{c}-0.048^{*} \\
(0.028)\end{array}$ & $\begin{array}{l}-0.025 \\
(0.019)\end{array}$ \\
\hline Bias-corrected & $\begin{array}{c}-0.138^{* *} \\
(0.055)\end{array}$ & $\begin{array}{c}-0.043^{*} \\
(0.025)\end{array}$ & $\begin{array}{l}-0.015 \\
(0.016)\end{array}$ & $\begin{array}{l}-0.019 \\
(0.058)\end{array}$ & $\begin{array}{c}-0.051^{*} \\
(0.028)\end{array}$ & $\begin{array}{l}-0.026 \\
(0.019)\end{array}$ \\
\hline Robust & $\begin{array}{c}-0.138^{* *} \\
(0.064)\end{array}$ & $\begin{array}{l}-0.043 \\
(0.030)\end{array}$ & $\begin{array}{l}-0.015 \\
(0.019)\end{array}$ & $\begin{array}{l}-0.019 \\
(0.068)\end{array}$ & $\begin{array}{l}-0.051 \\
(0.034)\end{array}$ & $\begin{array}{l}-0.026 \\
(0.023)\end{array}$ \\
\hline Observations & 1,577 & 1,577 & 1,953 & 1,430 & 1,577 & 1,714 \\
\hline \multicolumn{7}{|c|}{ Panel B: Secondary Qualification and Restricted Sample } \\
\hline Conventional & $\begin{array}{l}-0.056 \\
(0.064)\end{array}$ & $\begin{array}{c}0.002 \\
(0.027)\end{array}$ & $\begin{array}{c}0.010 \\
(0.016)\end{array}$ & $\begin{array}{c}0.007 \\
(0.069)\end{array}$ & $\begin{array}{l}-0.005 \\
(0.032)\end{array}$ & $\begin{array}{c}0.006 \\
(0.020)\end{array}$ \\
\hline Bias-corrected & $\begin{array}{l}-0.053 \\
(0.064)\end{array}$ & $\begin{array}{c}0.002 \\
(0.027)\end{array}$ & $\begin{array}{c}0.011 \\
(0.016)\end{array}$ & $\begin{array}{c}0.024 \\
(0.069)\end{array}$ & $\begin{array}{l}-0.003 \\
(0.032)\end{array}$ & $\begin{array}{c}0.007 \\
(0.020)\end{array}$ \\
\hline Robust & $\begin{array}{l}-0.053 \\
(0.077)\end{array}$ & $\begin{array}{c}0.002 \\
(0.033)\end{array}$ & $\begin{array}{c}0.011 \\
(0.020)\end{array}$ & $\begin{array}{c}0.024 \\
(0.081)\end{array}$ & $\begin{array}{l}-0.003 \\
(0.039)\end{array}$ & $\begin{array}{c}0.007 \\
(0.024)\end{array}$ \\
\hline Observations & 1,295 & 1,435 & 1,435 & 1,120 & 1,295 & 1,435 \\
\hline
\end{tabular}

Table 7 summarizes the results for the other measures of welfare we consider for the sub-sample whose highest qualification is at the secondary level. Just as in Table 6, panel A contains estimates derived using this sub-sample and panel $\mathrm{B}$ is the restricted version of this sample. Focusing on the estimates using the robust method, these results support the results in Table 6 Panel A and also provide a channel through which the noted reduction in poverty incidence occurs. These results suggests that treatment leads to higher wages of about 41,527 Naira which is substantial. Using log wage this result suggests a $38.2 \%$ increase in 
wages. ${ }^{19}$ For the secondary sample we do not see any effect on employment which is consistent with the lack of discontinuity in the $\mathrm{RD}$ plot (Figure $7 \mathrm{c}$ ). In the sample summarized in panel B where in previous estimation no effects have been noted, we find significant treatment effects using log wages but not wages and the estimated percentage increase in wages is larger 56.4\%. Again we also estimate these specifications on the sample in which we drop all individuals who enrolled in school after 6 (results not shown) and find magnitudes similar to those in Table 7 panel A for wages and similar to those in panel B for log wages. The effect of treatment on wages persist in this smaller sample using our robust method. However, the effect on log wage is not significant in the robust method but is significant in the bias corrected method.

\footnotetext{
${ }^{19}$ The log wage result is clearly significant in the first two methods and barely significant in the robust method ( $\mathrm{P}$ value 0.105$)$.
} 
Table 7: Does the 6-3-3-4 System Lead to Higher Wages, Employment and PCE: RD Estimates for Secondary Sample

\begin{tabular}{|c|c|c|c|c|c|}
\hline $\begin{array}{l}\text { RD } \\
\text { Method }\end{array}$ & $\begin{array}{l}\text { Wages } \\
(1)\end{array}$ & $\begin{array}{c}\mathrm{PCE} \\
(2)\end{array}$ & $\begin{array}{c}\text { Employed } \\
(3)\end{array}$ & $\begin{array}{c}\text { Log Wages } \\
\text { (4) }\end{array}$ & $\begin{array}{c}\log \text { PCE } \\
(5)\end{array}$ \\
\hline & \multicolumn{5}{|c|}{ Panel A: Sample with Secondary Qualification } \\
\hline Conventional & $\begin{array}{c}31,679.708^{*} \\
(18,968.552)\end{array}$ & $\begin{array}{c}-146.664 \\
(10,072.114)\end{array}$ & $\begin{array}{l}-0.054 \\
(0.046)\end{array}$ & $\begin{array}{l}0.335^{*} \\
(0.201)\end{array}$ & $\begin{array}{c}0.035 \\
(0.093)\end{array}$ \\
\hline Bias-corrected & $\begin{array}{c}41,527.875^{* *} \\
(18,968.552)\end{array}$ & $\begin{array}{c}-2,649.244 \\
(10,072.114)\end{array}$ & $\begin{array}{l}-0.068 \\
(0.046)\end{array}$ & $\begin{array}{l}0.382^{*} \\
(0.201)\end{array}$ & $\begin{array}{c}0.017 \\
(0.093)\end{array}$ \\
\hline Robust & $\begin{array}{l}41,527.875^{*} \\
(23,324.115)\end{array}$ & $\begin{array}{c}-2,649.244 \\
(11,500.895)\end{array}$ & $\begin{array}{l}-0.068 \\
(0.053)\end{array}$ & $\begin{array}{l}0.382^{*} \\
(0.236)\end{array}$ & $\begin{array}{c}0.017 \\
(0.109)\end{array}$ \\
\hline Observations & 335 & 1,238 & 867 & 601 & 1,427 \\
\hline \multicolumn{6}{|c|}{ Panel B: Secondary Qualification and Restricted Sample } \\
\hline Conventional & $\begin{array}{c}23,435.425 \\
(14,329.486)\end{array}$ & $\begin{array}{c}-4,849.494 \\
(11,806.819)\end{array}$ & $\begin{array}{c}-0.011 \\
(0.046)\end{array}$ & $\begin{array}{l}0.482^{*} \\
(0.247)\end{array}$ & $\begin{array}{l}-0.050 \\
(0.110)\end{array}$ \\
\hline Bias-corrected & $\begin{array}{l}25,599.456^{*} \\
(14,329.486)\end{array}$ & $\begin{array}{c}-4,490.188 \\
(11,806.819)\end{array}$ & $\begin{array}{l}-0.013 \\
(0.046)\end{array}$ & $\begin{array}{l}0.564^{* *} \\
(0.247)\end{array}$ & $\begin{array}{l}-0.061 \\
(0.110)\end{array}$ \\
\hline Robust & $\begin{array}{c}25,599.456 \\
(19,495.566)\end{array}$ & $\begin{array}{c}-4,490.188 \\
(13,912.288)\end{array}$ & $\begin{array}{l}-0.013 \\
(0.055)\end{array}$ & $\begin{array}{l}0.564^{*} \\
(0.305)\end{array}$ & $\begin{array}{l}-0.061 \\
(0.131)\end{array}$ \\
\hline Observations & 266 & 1,042 & 841 & 420 & 1,042 \\
\hline
\end{tabular}

The results thus far have been mixed but can be summarized as follows. While 6-3-3-4 system may have been deemed a total failure by many, these result suggests in its most conservative form that participants in this program are doing no worse than those who passed through the previous system. Moreover for the sample for which discernable effects are most likely- those whose highest qualification is at the secondary level, there is some evidence of a lower rate of extreme poverty (13.8\%) and evidence of wage increases (38.2\%). The noted positive effect on wages for treatment provides a likely channel for the noted effects on poverty 
incidence summarized in Table 6 .

\subsection{Robustness Checks}

One of the possible issues with examining the effect of the treatment on poverty is that poverty status is based on PCE which is linked with households income and not the income of an individual. In particular, if a married couple both earn income in the household and one is in the treatment group and the other is not, estimating the effect of treatment on PCE or poverty is more challenging because the dependent variable is determined by both husband and wife who have different treatment status. One way of dealing with this problem is to estimate a model with only single individuals. For this subgroup, direct links between expenditure and treatment may be inferred. The challenge for this estimation is sample size as most of those close to the cutoff are married by 2010-the period of the survey. Table 8 summarizes these results. The first three columns focuses on treatment effects based on the whole sample of singles and columns (3) to (6) summarizes the RD treatment effects for the restricted sample. Panel A summarizes estimates using the DPD measures while Panel B summarizes results for wages, employment and PCE. We are unable to derive estimates for those with secondary qualification who are single because the sample size of those close to the cutoff are too small for estimation. The results in Panel A suggest negative but insignificant effects of treatment on poverty for single individuals using the robust (preferred) method. However, we see positive significant effects of treatment on wages of single individuals. ${ }^{20}$ Finding positive effects on poverty status and wages is consistent with the results we noted in the overall sample though the magnitude is larger for the sample of single individuals. This result may suggest that the inference that ex-

\footnotetext{
${ }^{20}$ We also note significant effects when we use log wages instead of wages for the full sample but not for the restricted sample.
} 
posure to 6-3-3-4 reduces poverty risk may be spurious. However further analysis is needed to assert this given the sample size issue with this analysis.

Table 8: Do single individuals who passed through the 6-3-3-4 system have improved welfare? RD Estimates

\begin{tabular}{|c|c|c|c|c|c|c|}
\hline & \multicolumn{3}{|c|}{ All Single } & \multicolumn{3}{|c|}{ Restricted Sample } \\
\hline & (1) & $(2)$ & (3) & $(4)$ & $(5)$ & (6) \\
\hline $\mathrm{RD}$ & \multicolumn{6}{|c|}{ Panel A: Poverty Measures } \\
\hline \multirow[t]{2}{*}{ Method } & Poverty & Poverty & Poverty & Poverty & Poverty & Poverty \\
\hline & Status & Gap & Severity & Status & Gap & Severity \\
\hline \multirow[t]{2}{*}{ Conventional } & -0.176 & -0.121 & -0.095 & -0.176 & -0.132 & -0.103 \\
\hline & $(0.110)$ & $(0.083)$ & $(0.062)$ & $(0.122)$ & $(0.097)$ & $(0.073)$ \\
\hline \multirow[t]{2}{*}{ Bias-corrected } & -0.164 & $-0.143^{*}$ & $-0.111^{*}$ & -0.153 & $-0.160^{*}$ & $-0.123^{*}$ \\
\hline & $(0.110)$ & $(0.083)$ & $(0.062)$ & $(0.122)$ & $(0.097)$ & $(0.073)$ \\
\hline \multirow[t]{2}{*}{ Robust } & -0.164 & -0.143 & -0.111 & -0.153 & -0.160 & -0.123 \\
\hline & $(0.131)$ & $(0.102)$ & $(0.078)$ & $(0.145)$ & $(0.117)$ & $(0.088)$ \\
\hline \multirow[t]{3}{*}{ Observations } & 974 & 308 & 268 & 1,387 & 416 & 416 \\
\hline & \multicolumn{6}{|c|}{ Panel B: Other Welfare Measures } \\
\hline & Wages & PCE & Employed & Wages & PCE & Employed \\
\hline \multirow[t]{2}{*}{ Conventional } & $53,060.670^{*}$ & $10,493.970$ & 0.089 & $49,381.217^{*}$ & $-5,102.849$ & 0.050 \\
\hline & $(30,447.207)$ & $(31,188.013)$ & $(0.143)$ & $(29,294.727)$ & $(33,147.654)$ & $(0.137)$ \\
\hline \multirow[t]{2}{*}{ Bias-corrected } & $59,589.631^{*}$ & $10,361.562$ & 0.132 & $55,363.132^{*}$ & $-9,101.583$ & 0.085 \\
\hline & $(30,447.207)$ & $(31,188.013)$ & $(0.143)$ & $(29,294.727)$ & $(33,147.654)$ & $(0.137)$ \\
\hline \multirow[t]{2}{*}{ Robust } & $59,589.631^{*}$ & $10,361.562$ & 0.132 & $55,363.132^{*}$ & $-9,101.583$ & 0.085 \\
\hline & $(33,838.464)$ & $(37,266.481)$ & $(0.179)$ & $(32,882.772)$ & $(39,270.044)$ & $(0.160)$ \\
\hline Observations & 155 & 306 & 268 & 144 & 485 & 488 \\
\hline
\end{tabular}

A preferred way of dealing with the aforemention issue of linking treatment with poverty measures in households with dual or multiple earners is to focus on households with only one earner. This method is preferred to restricting the sample to those who are single because being single does not imply that the household head does not live within an extended family household were income is pooled. In households with only one income earner, we can link the treatment of the household head (who is typically the income earner) to the noted PCE 
and poverty status. Table 9 provides a summary of the estimated treatment effects for this sub-sample. For this sub-sample we cannot estimate the effect on employment because all the individuals in this sample are employed. In this analysis, although we also estimate effects on wages, we are most focused on the effect of treatment on poverty measures which are in panel A and PCE which is in panel B. These are the measures that typically are estimated from household expenditure and could pose an empirical challenge in households with more than one income earner where income earners can belong to different treatment status. The results suggest significant effects of treatment. Specifically we find that 6 3-3-4 reduces the probability of being poor. This result is robust to estimating treatment effects on the restricted sample. The results in table 8 also suggest increases in PCE for the treated sample but this effect is not significant in the restricted sample. Notice this effect is larger than previous noted effects in Table 3 and 4 . What these results may suggest is that earlier results for the effect of treatment on poverty risk were downward biased because treated individuals might have also had a non-treated member in the household which may have attenuated PCE. 
Table 9: RDD: Does exposure to 6-3-3-4 system improve welfare? (Single earner households) Robustness Checks

\begin{tabular}{lcccccc}
\hline & $(1)$ & All Single & \multicolumn{5}{c}{ Restricted Sample } \\
& \multicolumn{7}{c}{$(2)$} & $(3)$ & $(4)$ & $(5)$ & $(6)$ \\
\hline \hline Method & Poverty & Poverty & Poverty & Poverty & Poverty & Poverty \\
& Status & Gap & Severity & Status & Gap & Severity \\
\hline Conventional & $-0.235^{* * *}$ & $-0.119^{* *}$ & -0.042 & $-0.192^{* *}$ & -0.053 & -0.001 \\
& $(0.085)$ & $(0.046)$ & $(0.030)$ & $(0.088)$ & $(0.047)$ & $(0.030)$ \\
Bias-corrected & $-0.278^{* * *}$ & $-0.143^{* * *}$ & $-0.056^{*}$ & $-0.237^{* * *}$ & -0.074 & -0.011 \\
& $(0.085)$ & $(0.046)$ & $(0.030)$ & $(0.088)$ & $(0.047)$ & $(0.030)$ \\
Robust & $-0.278^{* * *}$ & $-0.143^{* * *}$ & $-0.056^{*}$ & $-0.237^{* *}$ & -0.074 & -0.011 \\
& $(0.094)$ & $(0.051)$ & $(0.033)$ & $(0.099)$ & $(0.052)$ & $(0.034)$ \\
Observations & 691 & 691 & 762 & 626 & 691 & 948 \\
\hline \multirow{5}{*}{ Method } & Wages & PCE & Log PCE & Wages & PCE & Log PCE \\
\hline Conventional & $84,561.466$ & $24,318.252^{*}$ & $0.365^{* *}$ & $57,897.233$ & $17,640.497$ & 0.142 \\
& $(84,441.308)$ & $(12,985.053)$ & $(0.151)$ & $(65,596.275)$ & $(12,936.297)$ & $(0.148)$ \\
Bias-corrected & $95,128.685$ & $25,003.626^{*}$ & $0.435^{* * *}$ & $52,391.865$ & $16,815.134$ & 0.196 \\
& $(84,441.308)$ & $(12,985.053)$ & $(0.151)$ & $(65,596.275)$ & $(12,936.297)$ & $(0.148)$ \\
Robust & $95,128.685$ & $25,003.626^{*}$ & $0.435^{* * *}$ & $52,391.865$ & $16,815.134$ & 0.196 \\
& $(101,478.016)$ & $(14,870.314)$ & $(0.168)$ & $(77,190.441)$ & $(14,653.600)$ & $(0.167)$ \\
Observations & 398 & 1,107 & 762 & 432 & 1,009 & 749 \\
\hline \hline
\end{tabular}

Our last robustness check is an attempt to estimate average treatment effects taking into consideration a common issue of unequal treatment of men and women in the labor market. Furthermore many women in Nigeria do not work outside the home so estimating treatment effects on the sample of men solely has value. These results are summarized in Table 10 . Specifically in Table 10 we present estimated LATE on poverty measures in Panel A and in Panel B we present estimates on employment, log wages and log PCE. In columns (1)-(3) estimates for all males are presented and in columns (4)-(6) estimates for those with secondary qualifications are presented. While we could not derive estimates for the sample of those whose 
highest qualification is at the secondary level when we considered single individuals and single earner households because of small sample size, when we consider all males, we have a large enough sample size so estimates for this sub-group can be derived. These results suggest that treatment leads to a $27.5 \%$ reduction in the probability of being poor for males with a secondary qualification. This is a significant effect of the system and relatively similar to the estimated impact noted when we consider single earner households. For the general population, we find negative but insignificant effects. If we focused solely on the sample of males that meet the requirements for our restricted sample(results not shown) we find negative but insignificant effect of program on poverty incidence. However if we dropped all those who enroll in school after 6 (results also not shown) we find significant estimates similar to those we find in the non-restricted sample. In particular we find that treatment leads to a $25.3 \%$ reduction in poverty likelihood for those with secondary qualifications.

Panel B summarizes the results for other poverty measures. We show only the results for log wage, employment and $\log$ PCE for brevity. We are particulary interested in the results for wages and employment because unlike poverty measures, treatment can be linked directly with individuals' wages. We find evidence that treatment increases wages for males by $36.8 \%$ and for males with secondary qualification, wages increase by $63.9 \%$. The estimated effect on wages for males with secondary qualification is twice the effect on the whole population (males and females) in panel A of Table 7. We do not find any significant effects on employment among males generally and among males with secondary qualification. If we use the restricted sample (results not shown) we find insignificant effects on wages for males in the general but in the sample with only those with secondary qualification, we find significant negative effects of treatment on males (wage increase of 64.3\%). In particular this estimate is similar to the estimate we find in Panel B, 
column (5). In monetary terms our result in Table 10 suggests that participation in the 6-3-3-4 system led to wage increases for males whose highest qualification is at the secondary level of about 32,536 Naira a year. ${ }^{21}$ Which amounts to about \$216 dollars per year (using an approximate 2010 dollar to Naira exchange rate). In contrast, similar analysis on both males and females in Table 7 column(4) panel A suggests a wage increase of 15,406 Naira. This difference in finding may suggest heterogeneity in the impact of treatment by gender. However more analysis beyond the scope of this paper is needed to assert this possibility.

Table 10: Robustness Checks: Do Males Who Pass Through the 6-3-3-4 system Experience Welfare Improvement?

\begin{tabular}{|c|c|c|c|c|c|c|}
\hline \multirow[t]{4}{*}{ RD Method } & \multicolumn{3}{|c|}{ All Males } & \multicolumn{3}{|c|}{ Males Secondary Qualification } \\
\hline & \multicolumn{6}{|c|}{ Panel A: Poverty Measures } \\
\hline & Poverty & Poverty & Poverty & Poverty & Poverty & Poverty \\
\hline & $\begin{array}{l}\text { Status } \\
(1)\end{array}$ & $\begin{array}{c}\text { Gap } \\
(2)\end{array}$ & $\begin{array}{c}\text { Severity } \\
(3)\end{array}$ & $\begin{array}{l}\text { Status } \\
(4)\end{array}$ & $\begin{array}{l}\text { Gap } \\
(5)\end{array}$ & $\begin{array}{c}\text { Severity } \\
(6)\end{array}$ \\
\hline \multirow[t]{2}{*}{ Conventional } & -0.045 & -0.014 & -0.002 & $-0.259^{* * *}$ & $-0.065^{*}$ & -0.013 \\
\hline & $(0.038)$ & $(0.019)$ & $(0.014)$ & $(0.079)$ & $(0.038)$ & $(0.025)$ \\
\hline \multirow[t]{2}{*}{ Bias-corrected } & -0.033 & -0.008 & 0.003 & $-0.275^{* * *}$ & $-0.074^{*}$ & -0.016 \\
\hline & $(0.038)$ & $(0.019)$ & $(0.014)$ & $(0.079)$ & $(0.038)$ & $(0.025)$ \\
\hline \multirow[t]{2}{*}{ Robust } & -0.033 & -0.008 & 0.003 & $-0.275^{* * *}$ & -0.074 & -0.016 \\
\hline & $(0.044)$ & $(0.023)$ & $(0.016)$ & $(0.094)$ & $(0.046)$ & $(0.030)$ \\
\hline \multirow[t]{3}{*}{ Observations } & 3,150 & 3,447 & 3,447 & 641 & 686 & 854 \\
\hline & \multicolumn{6}{|c|}{ Other Welfare Measures } \\
\hline & Employed & Log Wages & Log PCE & Employed & Log Wages & Log PCE \\
\hline \multirow[t]{2}{*}{ Conventional } & -0.018 & 0.292 & 0.024 & -0.032 & $0.541^{*}$ & 0.082 \\
\hline & $(0.027)$ & $(0.190)$ & $(0.072)$ & $(0.063)$ & $(0.282)$ & $(0.124)$ \\
\hline \multirow[t]{2}{*}{ Bias-corrected } & -0.024 & $0.368^{*}$ & -0.002 & -0.046 & $0.639^{* *}$ & 0.070 \\
\hline & $(0.027)$ & $(0.190)$ & $(0.072)$ & $(0.063)$ & $(0.282)$ & $(0.124)$ \\
\hline \multirow[t]{2}{*}{ Robust } & -0.024 & $0.368^{*}$ & -0.002 & -0.046 & $0.639^{* *}$ & 0.070 \\
\hline & $(0.031)$ & $(0.219)$ & $(0.082)$ & $(0.073)$ & $(0.325)$ & $(0.146)$ \\
\hline Observations & 1,533 & 801 & 2,752 & 486 & 288 & 850 \\
\hline
\end{tabular}

${ }^{21}$ Mean wages for males with secondary education in 2010 was $\$ 50917$. 


\section{Summary and Conclusion}

In this paper we considered the impact of the 6-3-3-4 system in Nigeria on welfare. This program was viewed by many as a flop leading to its replacement in 2006 . Given the program's goal of building self-reliant graduates through relevant education that has the potential to increase human capital accumulation, we focus on two question that allow us test to what extent this goal was achieved. Specifically we investigate if the 6-3-3-4 system participants experience welfare improvement in comparison to those who passed through the 6-5-4 system. We also consider if participants of this educational system are more likely to be employed given its emphasis on technology and building self-reliant graduates.

We examine several measures of welfare improvement. Specifically we consider poverty incidence, poverty gap, poverty severity, wages and PCE. We estimate LATE effects of treatment on these measure using an RD design suggested by CCT (2014) and the inference procedure and implementation command provided by the same authors. Using this command we derive estimated effects of treatment on the aforementioned indicators using a local linear polynomial estimator with a quadratic local polynomial bias correction. Given program participation is not based on choice but on year of birth, we do not worry about selectivity linked with choice. We derive estimates of treatment for the general population and for several sub-samples. In particular we are interested in the effect of treatment on those whose highest qualification is at the secondary level. This is the sample for which discernable effects of treatment, if they exist, are most likely to be found given most of the system changes that could affect welfare were implemented at this level. Our preferred results are based on the estimated effects for this sub-sample.

We conduct several robustness checks including estimating system effects on the sample of those who are single, households with just one income earner and 
males. Given some students enroll in school late and the rule of assignment to treatment which is year of birth would assign them to the control group instead of the treatment group, we also attempt to address the issue of misassignment close to the cutoff by creating a restricted sample in which we drop all who enroll after age 8 and reassign those who enroll at 7 and 8 who could be affected by this issue. However we are somewhat concerned with this sub-sample because of the select nature of those who enroll in school late. Given on average such individuals typically have lower welfare indicators, including them in treatment at the cutoff could attenuate our finding any effects of program participation.

Our results suggest that there is some evidence of welfare improvement from 6-3-3-4 especially at the secondary level. In particular if we consider the whole sample, our results suggest a $6.7 \%$ reduction in the probability of being in extreme poverty and for those with secondary qualification solely we find a $13.8 \%$ reduction in the probability of being in extreme poverty. If we consider households with single earners for which drawing a link between treatment and poverty status is more persuasive, we find effects of larger magnitudes (27.8\% reduction). We trace the channel of this impact on poverty by looking at the effect on wages. Our results suggest no significant effects on wage in the general sample but an increase of about 41,530 Naira in the secondary graduates sample. We do not find consistent evidence of a statically increase in employment for participants of the 6-3-3-4 system although many of the estimate are positive. ${ }^{22}$. While we find some evidence of increase in PCE and a reduction in the poverty gap and severity among the treated group in some samples, in most cases non-significant effects are noted.

The results from our analysis are important because the 6-3-3-4 system got

\footnotetext{
${ }^{22}$ The exception being in Table 5 when we focus on the restricted sample and find significant positive effects on employment of about $5.3 \%$.
} 
changed to another education system 9-3-4 in 2008 without any critical evaluation of the 6-3-3-4 systems impacts. Rather, anecdotal evidence and qualitative evidence suggesting the program was a total failure played a significant role in getting the system dropped. In November 2014, the 9-3-4 system got modified with the introduction of the 1-6-3-3-4 education policy. There is suggestive evidence that this change was again made without significant quantitative evaluation. Given this trend, providing the first quantitative evaluation of the 6-3-3-4 system despite the limitations in the analysis with respect to external validity is useful. The few in support of the program have argued that the issue with the program was not the objectives of the 6-3-3-4 system, its process, action steps, setup or content but rather its poor implementation (Fafunwa 2005). Our results support this position. Despite claims of poor implementation of the program in many schools, our results suggest that there is evidence of some positive effects at the level most of the education system's changes were focused on (secondary education).

As discussions are still underway to develop a new education policy in Nigeria, it is important that policymakers are made aware of the need for good quantitative evaluation of an education system before change. A program or system change is costly not only for the tax payer but for the consumers of education and such a change should only be undertaken after careful evaluation. Our paper is just a starting point that we hope will propel more quantitative analysis of this past system. In our paper, the extent to which we are able to fine tune the sample of our treated and control group has been limited by sample size. Hence we are a bit reluctant to claim our results capture the full effect of the system on reducing poverty incidence and increasing employment even for secondary school graduates. What our results suggest is that there are significant positive effects of exposure to the 6-3-3-4 system especially for individuals at the secondary level and our results are likely a lower bound. Moreover our results only provide LATE and the effect 
of the system on the population may be different. Finally, more empirical analysis with detailed data on exposure to treatment and a larger sample of individuals in the control and treatment sample is useful, and needed.

\section{References}

[1] Angrist, J., and V. Lavy. (1999). Using Maimonides' Rule to Estimate the Effect of Class Size on Student Achievement. Quarterly Journal of Economics 114: 535-575.

[2] Angrist, Joshua; Bettinger, Eric; Bloom, Erik; King, Elizabeth and Kremer, Michael (2002). Vouchers for Private Schooling in Colombia: Evidence from a Randomized Natural Experiment. American Economic Review, 92(5), December, 1535-1558.

[3] Angrist, Joshua, Eric Bettinger, and Michael Kremer. (2006). Long-term educational consequences of secondary school vouchers: Evidence from administrative records in Colombia." The American Economic Review: 847-862.

[4] Ajetomobi J, O and Ayanwale and A, B (2005). Education allocation, unemployment and economy growth in Nigeria: 1970-2004. retrived on July 24 2013 from http://www. saga. cornell. edu/saga/educconf/ajetomobi.pdf

[5] Awogbenle, A. Cyril, and K. Chijioke Iwuamadi. (2010). Youth unemployment: Entrepreneurship development programme as an intervention mechanism. African Journal of Business Management 4.6: 831-835.

[6] Behrman, Jere, Susan Parker, and Petra Todd. (2009). "Long-Term Impacts of the Oportunidades Conditional Cash-Transfer Program on Rural Youth in Mexico." In Poverty, Inequality, and Policy in Latin America, ed. Stephan Klasen and Felicitas Nowak-Lehmann, 219-70. Cambridge, MA: MIT Press.

[7] Calonico, Sebastian, Matias D. Cattaneo, and Rocio Titiunik.(2014).Robust data-driven inference in the regression-discontinuity design. Stata Journal 14.4: 909-946.

[8] Calonico, S., M. D. Cattaneo, and R. Titiunik (2014). Robust nonparametric confidence intervals for regression-discontinuity designs. Econometrica 82: 2295-2326. 
[9] de Janvry, Alain, Frederico Finan, Elisabeth Sadoulet, and Renos Vakis. (2006). Can Conditional Cash Transfer Programs Serve as Safety Nets in Keeping Children at School and from Working When Exposed to Shocks? Journal of Development Economics 79: (2) 349-73.

[10] Dynarski, Susan, (2003). The Consequences of Merit Aid, NBER Working Paper 9400.

[11] Duflo Esther., (2001). Schooling and Labor Market Consequences of School Construction in Indonesia: Evidence from an Unusual Policy Experiment. American Economic Review, vol. 91, issue 4, pages 795-813.

[12] Gonzalez, Naihobe, and Ruth Uwaifo Oyelere. (2011) Are returns to education on the decline in Venezuela and does Mission Sucre have a role to play?. Economics of Education Review 30.6: 1348-1369.

[13] Fafunwa, A.B. (1974) A History of Education in Nigeria (London, George Allen \& Unwin).

[14] Fleisher, B. M., Sabirianova,P. K., Wang, X., 2005. Returns to skills and the speed of reforms: evidence from Central and Eastern Europe, China, and Russia. Journal of Comparative Economics 33 (2),351.

[15] Farlie and Robinson. (2013). Experimental Evidence on the effects of home computer on academic achievement among school children American Economic Journal: Applied Economics, 5(3): 211-240.

[16] Hauwa Imam (2012) Educational Policy in Nigeria from the Colonial Era to the Post-Independence Period. Italian Journal of sociology of education 1.

[17] Jalan, Jyotsna, and Martin Ravallion. (2003). Estimating the Benefit Incidence for an Antipoverty Program by Propensity-Score Matching. Journal of Business and Economic Statistics 21 (1): 19-30.

[18] Jacob, B. A., and L. Lefgren, L. (2006). Remedial Education and Student Achievement: A Regression-Discontinuity Analysis. The Review of Economics and Statistics 86 (1): 226-244.

[19] Kremer, Paul, Paul Kremer with Paul Glewwe, Sylvie Moulin and Eric Zitzewitz, (2004). Retrospective vs. Prospective Analyses of School Inputs: The Case of Flip Charts in Kenya", Journal of Development Economics 74(1), pp. 251-268. 
[20] Kremer, Paul and Edward Miguel (2004) Worms: Identifying Impacts on Education and Health in the Presence of Treatment Externalities, Econometrica 72(1), pp. 159-217.

[21] Kremer, Paul, Josh Angrist and Eric Bettinger. (2005). Long-Term Educational Consequences of Secondary School Vouchers: Evidence from Administrative Records in Colombia, American Economic Review. 96(3) pp 847-862.

[22] Krueger, Alan and Whitmore, Diane, (2001) The Effect of Attending a Small Class in the Early Grades on College-Test Taking and Middle School Test Results: Evidence from Project STAR, Economic Journal, 11(468).

[23] Krueger, Alan and Pei Zhu, (2003) Another Look at the New York City School Voucher Experiment, NBER Working Paper 9418.

[24] Lemieux, T., and K. Milligan. 2004. Incentive Effects of Social Assistance: A Regression Discontinuity Approach (NBER Working Paper 10541). Cambridge, MA: National Bureau of Economic Research.

[25] Ludwig, J., and D. Miller, (2007), Does Head Start Improve Children.s Life Chances? Evidence from a Regression Discontinuity Design, Quarterly Journal of Economics 122(1),159-208.

[26] Matsudaira, J. D. (2008). Mandatory summer school and student achievement. Journal of Econometrics, 142(2), 829-850.

[27] McEwan, P. J., and J. S. Shapiro. (2008). The Benefits of Delayed Primary School Enrollment: Discontinuity Estimates Using Exact Birth Dates. Journal of Human Resources 43 (1): 1-29.

[28] NBS (2010) National manpower stock and employment generation survey.

[29] Osili, Una Okonkwo, and Bridget Terry Long. (2008) Does female schooling reduce fertility? Evidence from Nigeria. Journal of Development Economics 87.1 (2008): 57-75.

[30] Oyelere, Ruth Uwaifo. (2010) Africa's education enigma? The Nigerian story. Journal of Development Economics 91.1: 128-139.

[31] Oyelere, Ruth Uwaifo. (2011). Have Returns to Education Changed in Nigeria? Uncovering the Role of Democratic Reforms. Journal of African Economies 20.5: 737-780. 
[32] Rouse, Cecilia Elena, (1998) Private School Vouchers and Student Achievement: An Evaluation of the Milwaukee Parental Choice Program, Quarterly Journal of Economics, 13(2), 1998, 553-602.

[33] Thovoethin, Paul-Sewa privitization of education and the 6-3-3-4 education system in Nigria: a critical assesment. Paper Presented at the Open Society Initiative for Southern Africa retrivied on July 17th 2013. http://www. periglobal.org/sites/periglobal.org/files/9.Privatisation_of_ Education_and_6-3-3-4_Educational_System_Nigeria(Thovoethin). pdf

[34] Thistlewaite, D., and D. Campbell, (1960), Regression-Discontinuity Analysis: An Alter- native to the Ex-Post Facto Experiment, Journal of Educational Psychology 51, 309-317.

[35] Todd, Petra, and Kenneth Wolpin. 2006. Assessing the Impact of a School Subsidy Program in Mexico: Using a Social Experiment to Validate a Dynamic Behavioral Model of Child Schooling and Fertility. American Economic Review 96 (5): 1384-417.

[36] Uwaifo V. O and Uddin P.S.O. (2009) Transition from the 6-3-3-4 to the 9-34 System of Education in Nigeria: An Assessment of Its Implementation on Technology Subjects. Stud Home Comm Sci, 3(2): 81-86.

[37] World Bank (2011) Retirement ages, The International Bank for Reconstruction and Development. Retrieved 31st August, 2011, http:// wbl. worldbank. org/data/exploretopics/getting-a-job\#Retirement $\% 20$ ages $>$

[38] Van der Klaauw, Wilbert. (2002). Estimating the Effect of Financial Aid Offers on College Enrollment: A Regression-Discontinuity Approach. International Economic Review 43.4): 1249-1287. 